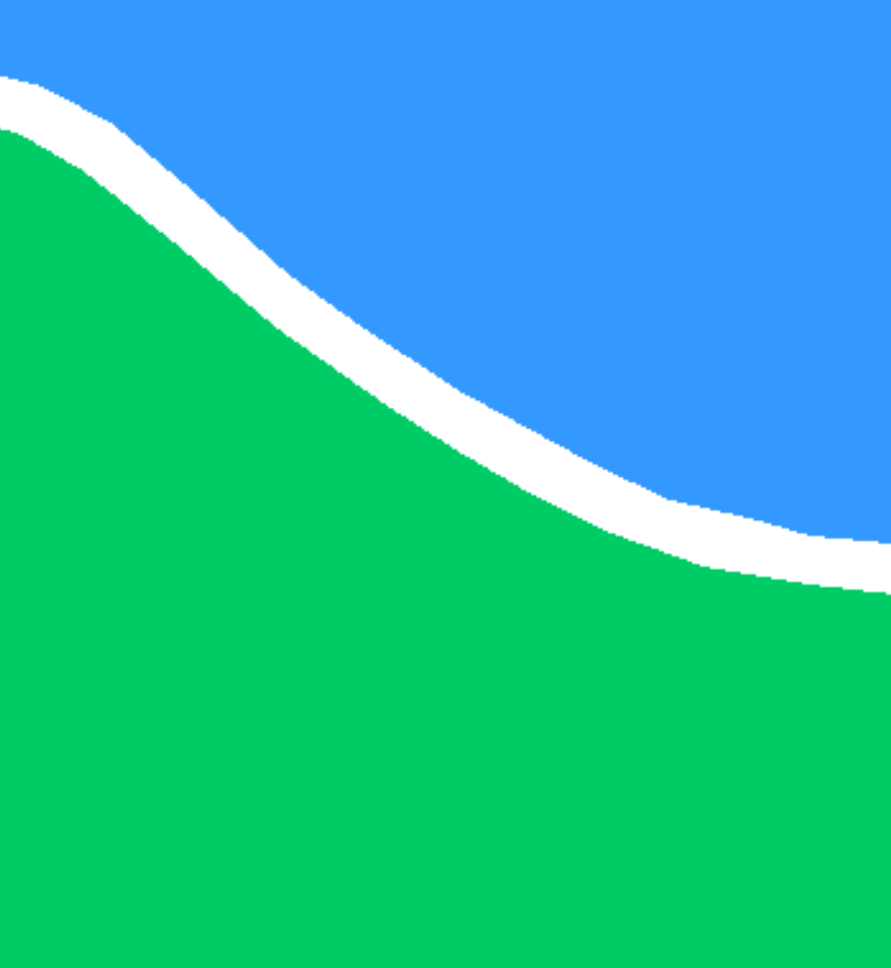

TRABALHO DE GRADUAÇÃO

\title{
ANÁLISE DOS EFEITOS DA NÃO LINEARIDADE DO AMPLIFICADOR NO DESEMPENHO DE UM SISTEMA OFDM
}

Ian Alves Ulian

\section{UNIVERSIDADE DE BRASÍLIA}


UNIVERSIDADE DE BRASILIA

Faculdade de Tecnologia

\title{
TRABALHO DE GRADUAÇÃO
}

\section{ANÁLISE DOS EFEITOS DA NÃO LINEARIDADE DO AMPLIFICADOR NO DESEMPENHO DE UM SISTEMA OFDM}

\author{
Ian Alves Ulian \\ Relatório submetido ao Departamento de Engenharia \\ Elétrica como requisito parcial para obtenção \\ do grau de Engenheiro Eletricista
}

Banca Examinadora 
Prof. Dr. Paulo H. P. de Carvalho,

$\mathrm{ENE} / \mathrm{UnB}$

Orientador

Prof. Dr. André N. Barreto, INdT

Orientador

Prof. Dr. Leonardo Aguayo, INdT

Examinador externo

Prof. Dr. Leonardo R. A. X. de Menezes,

$\mathrm{ENE} / \mathrm{UnB}$

Examinador interno 


\section{Dedicatória}

Dedico à todos que me incentivaram e me ajudaram no seu desenvolvimento.

Ian Alves Ulian 


\section{Agradecimentos}

Primeiramente ao Eterno, que me deu força e perseverança para chegar até aqui. Aos meus pais, que me deram os princípios, a educação e o carinho necessários a um filho, o que permitiu a realização desse sonho. À minha irmã Samanta, pelo apoio e companheirismo sem igual. Ao meu irmão Ravi, pela amizade e diversão que encontro dentro de casa. Aos meus amigos irmãos, que ocupam lugar especial em minha vida. Aos meus amigos da Elétrica, que fizeram do curso uma festa, um momento fantástico em minha vida. Ao pessoal do projeto WiSiL, que compartilharam minhas dúvidas e ajudaram no desenvolvimento do meu conhecimento. E, por fim, aos meus orientadores André Barreto e Paulo Portela, que compartilharam de seu nobre conhecimento e tornaram o desenvolvimento deste trabalho um aprendizado imenso.

Ian Alves Ulian 


\section{RESUMO}

A grande necessidade mundial por acesso rápido a informação de alta qualidade, seja ela texto, imagem, voz ou vídeo, demandou esforços no sentido da existência de tecnologias capazes de satisfazer tal requisito. Portanto, elas devem, basicamente, promover altas taxas de transmissão nos mais diversos ambientes de propagação. Foi nesse contexto que a técnica de modulação por múltiplas portadoras OFDM (Orthogonal Frequency Division Multiplexing) ganhou popularidade, uma vez que satisfaz vários requisitos necessários a sistemas de transmissão digital de sinais. Também, nesse sentido, está o desenvolvimento dos padrões de transmissão LTE (Long Term Evolution) e WiMAX (Worldwide Interoperability for Microwave Access), os quais utilizam OFDM em sua camada física.

Apesar das inúmeras vantagens do OFDM, na presença de um amplificador não linear no sistema transmissor, a sua grande variação de amplitude gera algumas entraves como distorção do sinal trasmitido e radiação fora de banda. Logo, um importante aspecto no projeto do sistema é tornar o sinal a ser transmitido o menos sensível possível a não linearidade do amplificador.

Neste trabalho, o esquema OFDM será detalhado assim como o padrão WiMAX será introduzido. Além disso, será feito um estudo da variação do envelope de um sinal OFDM por meio de uma análise de PAPR (Peak-to-Average Power Ratio) e será analisado o desempenho do sistema na presença de diferentes tipos de amplificadores. Logo em seguida, serão introduzidas técnicas de mitigação das não linearidades de um sistema OFDM com o intuito de melhorar o seu desempenho.

\section{ABSTRACT}

The world's big necessity of quick access to high quality information in text, image, voice or video, required some efforts for the existence of technologies which can meet this requirements. Therefore, they basically need to promote high trasmission rates in the most differents enviroments of propagation. It was in that context that the modulation technique OFDM (Orthogonal Frequency Division Multiplexing) gained popularity, since it satisfies many requirements that a digital signal trasmition system needs. Also, in that sense, are the standards that describe the technologies LTE (Long Term Evolution) and WiMAX (Worldwide Interoperability for Microwave Access).

In spite of OFDM's many advantages, in the presence of a non linear amplifier in the transmitter, its wide range of amplitude generates some issues as the signal distortion and 
out of band radiation. Thus, an important aspect of the system project is to make the signal as least sensitive to the amplifier non linearity as possible.

In this work, the OFDM is detailed and the WiMAX standard is introduced. Besides, it will be done a study of the envelope variation of an OFDM signal using his PAPR (Peakto-Average Ratio) analysis and it will be analised the system performance in the presence of differents kinds of amplifiers. Then, it will be introduced some techniques to mitigate the non linearities effects of an OFDM system with the purpose to improve the system performance. 


\section{SUMÁRIO}

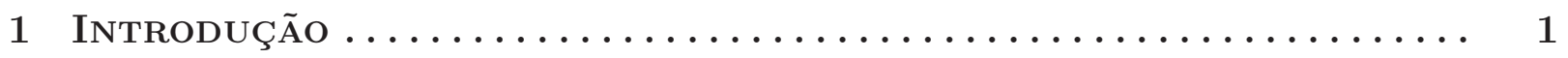

1.1 Os Sistemas de Comunicação Celular Móvel $\ldots \ldots \ldots \ldots \ldots \ldots \ldots \ldots \ldots$

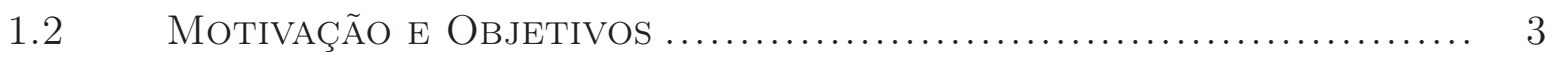

1.3 Estrutura do trabalho ...................................... 4

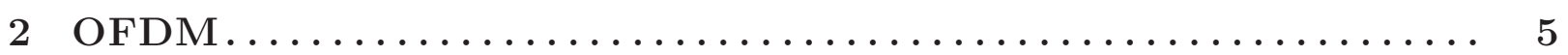

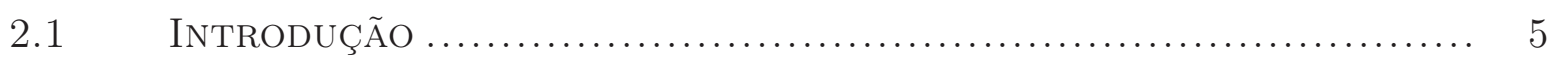

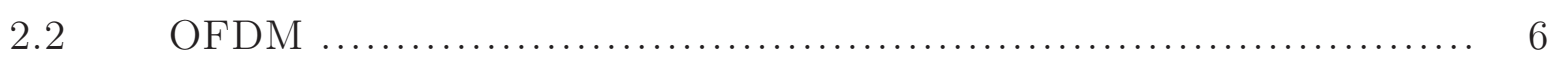

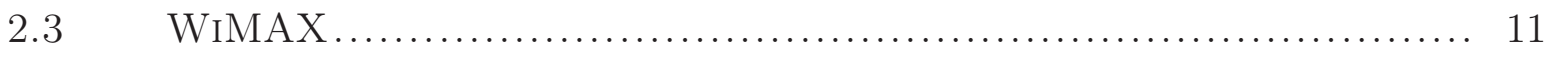

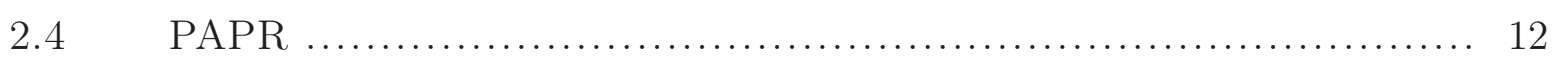

3 OFDM COM AMPLIFICAÇÃ̃ NÃO LINEAR.................. 16

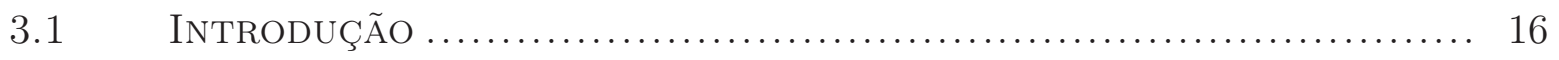

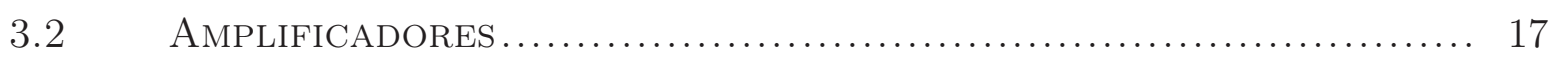

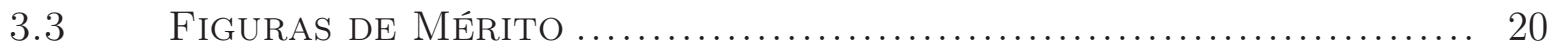

4 Técnicas de mitigação de não linearidades em OFDM $\ldots \ldots \ldots 25$

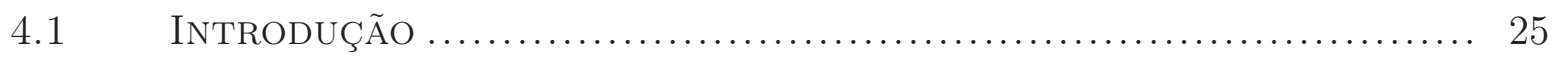

4.2 MÉTODO DE clipping ........................................... 26

4.3 MÉTOdO DE JONES ............................................... 27

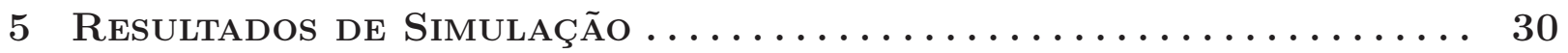

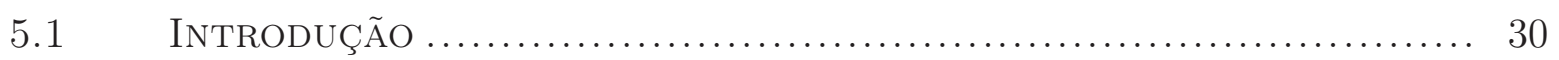

5.2 Desempenho dos AMPLIFICAdoRES .............................. 31

5.3 Desempenho do WimaX Móvel ................................. 35

5.4 Avaliação do MÉTOdo de clipping ................................ 37

5.5 Avaliação do MÉtodo de Jones.................................... 40

6 Conclusões e Trabalhos Futuros $\ldots \ldots \ldots \ldots \ldots \ldots \ldots \ldots \ldots \ldots$

REFERÊNCIAS BIBLIOGRÁFICAS .................. 50 


\section{LISTA DE FIGURAS}

2.1 Canal seletivo em frequência ............................................ 6

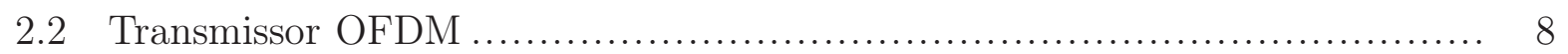

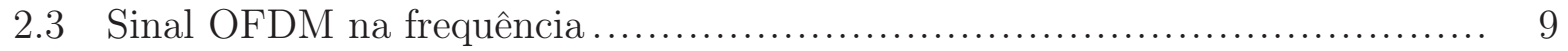

2.4 Distribuição estatística da parte real das amostras de um sinal OFDM ao

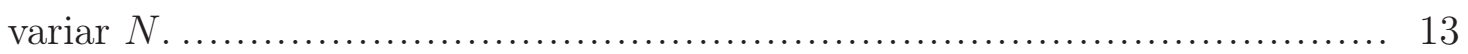

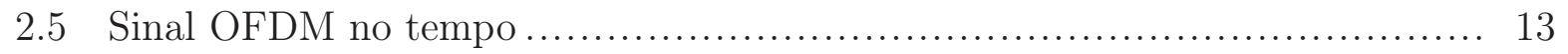

2.6 CDF de PAPR de sinais OFDM filtrado e não filtrado ........................ 14

2.7 CDF de PAPR de sinais OFDM com diferentes números de subportadoras ... 15

2.8 CDF de PAPR de sinais OFDM com diferentes modulações .................. 15

3.1 Características das conversões AM/AM e AM/PM para o amplificador modelo de Saleh............................................................ 18

3.2 Função de Transferência dos Amplifificadores Rapp e limitador de envelope... 19

3.3 Função de Transferência de um Amplificador Não Linear Genérico ............. 20

3.4 Constelação de um sinal após passar por um amplificador de Saleh............ 20

3.5 Constelação de um sinal após passar por um amplificador Rapp............... 21

3.6 BER x EbNo para diferentes valores de OBO ............................. 23

3.7 Degradação Total para um canal AWGN e $B E R=10^{-4} \ldots \ldots \ldots \ldots \ldots \ldots \ldots \ldots \ldots \ldots . . . \ldots 23$

3.8 Densidade Espectral de Potência de sinais OFDM ............................ 24

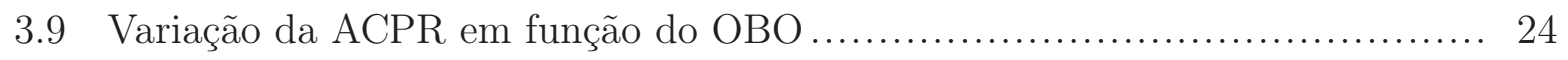

4.1 Sinal OFDM no tempo .............................................. 26

4.2 Sinal OFDM no tempo após clipping ................................... 26

4.3 Constelação após aplicação do método de Jones para o 16 QAM .............. 27

4.4 Constelação após aplicação do método de Jones para o QPSK ................. 29

4.5 Constelação após aplicação do método de Jones para o 64 QAM ............... 29

5.1 Degradação Total de um sistema OFDM utilizando amplificadores Rapp ..... 31

5.2 Degradação Total de um sistema OFDM utilizando amplificadores Rapp ..... 32

5.3 ACPR em função do OBO utilizando amplificadores Rapp .................... 33

5.4 Degradação Total para diferentes tipos de amplificadores..................... 33

5.5 Degradação Total para diferentes tipos de amplificadores...................... 34

5.6 Degradação Total para diferentes tipos de amplificadores...................... 35 
5.7 Densidade Espectral de Potência de sinais OFDM .......................... 35

5.8 Degradação Total para diferentes amplificadores ............................ 36

5.9 Degradação Total para diferentes amplificadores ............................ 37

5.10 CDF de PAPR de um sinal OFDM ao se utilizar o método de clipping ......... 38

5.11 Degradação Total com a utilização de clipping ............................... 38

5.12 Constelação de um sinal OFDM modulado em QPSK clipado em 60\% de sua máxima amplitude................................................. 39

5.13 Constelação de um sinal OFDM modulado em QPSK clipado em 40\% de sua máxima amplitude

5.14 CDF de PAPR de um sinal OFDM sem e com redução de PAPR variando o valor de $L$ max....

5.15 Degração Total para avaliação do método de Jones............................. 41

5.16 OBO ótimo em função do número máximo de iterações ........................ 42

5.17 Degradação Total mínima em função do número máximo de iterações ......... 43

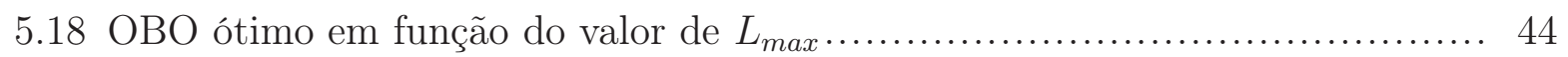

5.19 Degradação Total mínima em função do valor de $L_{\max } \ldots \ldots \ldots \ldots \ldots \ldots \ldots \ldots \ldots \ldots . \ldots . \ldots \ldots$

5.20 Degradação Total utilizando QPSK, 16 QAM e 64 QAM ....................... 45

5.21 Espectro de um sinal OFDM com e sem redução de PAPR, Amplificador

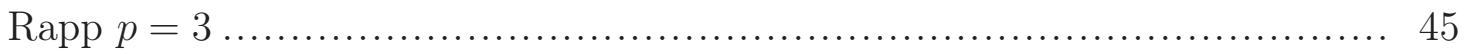

5.22 Variação do ACPR para diferentes valores de OBO .......................... 46 


\section{LISTA DE TABELAS}

2.1 Parâmetros do OFDM utilizados no WiMAX .............................. 11 


\section{LISTA DE SÍMBOLOS}

\section{Siglas e Abreviações de Língua Inglesa}

AMPS Advanced Mobile Phone System

AWGN Additive White Gaussian Noise

BER Bit Error Rate

CDF Cumulative Distribution Function

CDMA Code Division Multiple Access

DFT Discrete Fourier Transform

EGPRS Enhanced General Packet Radio Service

FDMA Frequency Division Multiple Access

FFT Fast Fourier Transform

GMSK Gaussian Minimum Shift Keying

GPRS General Packet Radio Service

GSM Global System for Mobile Communications

HSDPA High Speed Dowlink Packet Access

HSPA High Speed Packet Aceess

HSUPA High Speed Uplink Packet Access

IBO Input Backoff

ICI Inter-Carrier Interference

IFFT Inverse Fast Fourier Transform

ISI Inter-Symbol Interference

OBO Output Backoff

OFDM Orthogonal Frequency Division Multiplex

OFDMA Orthogonal Frequncy Division Multiple Access

PAPR Peak-to-Average Power Ratio

PAR Peak to Average Ratio

PSD Power Spectral Density

QAM Quadrature Amplitude Modulation

QPSK Quadrature Phase Shift Keying

TDMA Time Division Multiple Access

TWT Travelling Wave Tube

UMTS Universal Mobile Telecommunications System

WCDMA Wideband Code Division Multiple Access

WiMAX Worldwide Interoperability for Microwave Access

3G LTE Third Generation Long Term Evolution 
Siglas e Abreviações de Língua Portuguesa

DT Degradação Total 


\section{Capítulo 1}

\section{Introdução}

Neste capítulo é feita uma contextualização do tema, apresentados os desafios que culminaram na realização do trabalho e seus objetivos. Além disso, a estrutura do trabalho é apresentada.

\subsection{Os Sistemas de Comunicação Celular Móvel}

Quando o modelo por comunicação móvel em células foi concebido, não se imaginava transmissões digitais com altas taxas, onde seria possível a trasmissão de imagem ou vídeo por um simples dispositivo móvel. Não se imaginava, também, a enorme aceitação mundial desse serviço. No entanto, houve uma grande evolução nos sistemas de transmissão desde então, o que culminou na possibilidade de se realizar, dentre outras ações, uma chamada de vídeo ou o acesso a um canal de televisão por meio de um dispositivo móvel em diferentes ambientes ou até mesmo em movimento. Além disso, houve um aumento expressivo no número de usuários, o que é consequência tanto da facilidade de comunicação existente quanto dos outros possíveis serviços possíveis de serem explorados.

Esse tipo de comunicação em células teve início na década de 80 e o primeiro sistema móvel celular a se estabelecer na América foi o sistema denominado AMPS (Advanced Mobile Phone System - Sistema avançado de telefonia móvel), que representou a primeira geração de telefonia celular. Apesar de ser uma inovação, a finalidade do sistema em questão era realizar somente chamadas analógicas de voz e enviar pequenos recados.

Já na década de 90, foi dado um passo significativo na evolução dos sistemas móveis celulares quando a transmissão analógica começou a dar lugar a transmissão digital. Deu-se início, então, à segunda geração de telefonia celular, por meio da qual já era possível serviços como o envio de mensagens de texto e o acesso ao correio de voz. Os maiores expoentes dessa geração no Brasil foram os sitemas IS-136 ou TDMA (Time Division Multiple Access Acesso por Divisão Temporal), GSM (Global System for Mobile Communications - Sistema global para comunicações móveis) e o IS-95 ou CDMA (Code Division Multiple Access - 
Acesso por Divisão em Códigos). Com a utilização desses sistemas era possível chegar a uma taxa da ordem de 10 kbps por usuário.

Entre as chamadas segunda e terceira gerações, aconteceram evoluções que merecem destaque como o surgimento do GPRS (General Packet Radio Service - Serviço de rádio para transmissão de pacotes em geral), que permitia a transmissão de até 144 kbps por usuário, e do EGPRS (Enhanced General Packet Radio Service - Serviço elevado de rádio para transmissão de pacotes em geral), com o qual era possível chegar a transmissões de 384 kbps individualmente. Como consequência foram classificadas como tecnologias 2,5G, uma vez que eram uma evolução da geração anterior, mas ainda não eram dignas de serem classificadas em uma geração posterior. Ao trafegar dados IP e utilizar a estrutura da rede GSM, já era possível, nessa altura, visualição de páginas web e navegação na internet por meio de um dipositivo móvel.

Por volta do ano 2000, começaram a surgir os sistemas de telefonia móvel classificados como de terceira geração. O mais conhecido no Brasil é o UMTS (Universal Mobile Telecommunications System - Sistema Universal de Telecomunicações Móveis), por meio do qual é possível realizar uma videoconferência e assistir a canais de televisão com o celular. Essa geração promete até 2 Mbps de taxa de transmissão por usuário.

Como um adendo à terceira geração, foi proposta a tecnologia HSPA (High Speed Packet Access - Acesso por pacotes em alta velocidade), que possibilita maiores taxas de transmissão tanto no enlace direto com a utilização do HSDPA (High Speed Dowlink Packet Access - Acesso por pacotes em alta velocidade no enlace direto) quanto no enlace reverso ao se utilizar o HSUPA (High Speed Uplink Packet Access - Acesso por pacotes em alta velocidade no enlace reverso). Consequentemente, ela foi enquadrada como tecnologia 3,5G.

Até o presente momento, a quarta geração ainda está por vir. No entanto, estudos e propostas já vem sendo feitas no sentido de aperfeiçoar a terceira geração. Uma dessas propostas é denominada 3G LTE (Third Generation Long Term Evolution - Evolução à longo prazo para a terceira geração de sistemas móvel celular), que consiste, basicamente, em uma evolução para o UMTS. Outra tecnologia que aponta no sentido da quarta geração é chamada de WiMAX ( Worldwide Interoperability for Microwave Access - Interoperabilidade para acesso por microondas pelo mundo). É interessante destacar que ambas têm como técnica de transmissão o OFDM (Orthogonal Frequency Division Multiplex - Multiplexação por divisão em frequências ortogonais) e suporte para múltiplas antenas na transmissão e na recepção. Assim, pretende-se chegar a taxas de transmissão de até 100 Mbps.

Ao se observar a evolução das tecnologias, dois aspectos merecem destaque na análise. O primeiro diz respeito à técnica de modulação empregada. No AMPS, utilizava-se modulação analógica para a transmissão de voz. No GSM, passou a se utilizar, para transmitir voz, a modulação GMSK (Gaussian Minimum Shift Keying - Chaveamento por deslocamento mínimo utilizando filtro gaussiano), onde cada símbolo era composto por um bit. Já 
no UMTS, a modulação utilizada é QPSK (Quadrature Phase Shift Keying - Chaveamento por deslocamento de fase em quadratura), na qual dois bits formam um símbolo. Finalmente, para o LTE e WiMAX, são propostas as modulações QPSK, 16 QAM (Quadrature Amplitude Modulation - Modulação por amplitude em quadratura) e 64 QAM, onde um símbolo é composto, respectivamente, por dois, quatro e seis bits.

Nota-se, portanto, que a tendência é a utilização de esquemas de modulação que portam maior quantidade de bits por símbolo. No entanto, essa atitude deve ser respaldada por melhores receptores e por técnicas que amenizem o efeito do ruído e da interferência geradas no sinal.

O segundo aspecto merecedor de destaque diz respeito à forma de acesso à rede de transmissão. Seguindo a ordem cronológica da utilização das tecnologias, ou seja, AMPS, IS136, GSM, UMTS notou-se a seguinte ordem de esquemas de acesso à rede: FDMA, TDMA, TDMA/FDMA, WCDMA. Por fim, os padrões LTE e WiMAX propõem a utilização do OFDMA.

\subsection{Motivação e Objetivos}

O esquema de transmissão OFDM é, de fato, o esquema a ser adotado pelas gerações futuras de telefonia celular. A justificativa para isso consiste no fato de que ele possui inúmeras vantagens, dentre elas podem ser citadas:

- Robustez contra desvanecimento seletivo em frequência e dispersão temporal

- Equalização com baixa complexidade computacional com a implementação da FFT

No entanto, o esquema em questão também possui algumas desvantagens como:

- Sensibilidade a desvio de frequência

- Sensibilidade aos efeitos não lineares de um amplificador

- Perda de potência e de eficiência espectral devido ao prefixo cíclico

- Sensibilidade ao ruído de fase do oscilador

Portanto, com a finalidade de tornar o OFDM mais vantajoso do que já é, deve-se tentar amenizar suas desvantagens. Foi nesse sentido que o trabalho foi realizado.

Focamos na sensibilidade aos efeitos não lineares de um amplificador com a intenção de avaliar as razões e as consequências da ocorrência desse aspecto negativo. Além disso, tentou-se amenizar esse efeito com a finalidade de melhorar uma transmissão OFDM. 


\subsection{Estrutura do trabalho}

No Capítulo 2 é feita uma breve descrição sobre o padrão WiMAX. Além disso, é realizada uma abordagem sobre o esquema de transmissão OFDM. Por fim, é definida uma das principais ferramentas de análise do trabalho: o PAPR (Peak-to-Average Power Ratio - Razão entre potência de pico e potência média).

No Capítulo 3, o comportamento de um sinal OFDM na presença de um amplificador não linear é descrito. Ademais, são detalhados os tipos de amplificadores e introduzidas as figuras de mérito utilizadas no trabalho.

As técnicas utilizadas para reduzirem o PAPR do sinal e mitigar os efeitos da não linearidade de um amplificador são detalhados no Capítulo 4.

Os resultados obtidos são apresentados e analisados no Capítulo 5 e, por fim, o capítulo 6 traz as conclusões obtidas e propostas para futuros estudos. 


\section{Capítulo 2}

\section{OFDM}

Este Capitulo apresenta uma breve introdução ao OFDM assim como a descrição de algumas características da camada física da tecnologia WiMAX. Por fim, a figura de mérito PAPR é abordada bem como é feita uma análise de sua presença em um sinal OFDM.

\subsection{Introdução}

A modulação por múltiplas portadoras OFDM (Orthogonal Frequency Division Multiplexing) ganhou grande aceitação no mundo das comunicações de altas taxas de transmissão e, então, tem se tornado a base para diversos padrões de transmissão sem fio. São exemplos desse fato os padrões WiFi IEEE 802.11a [1], WiMAX IEEE 802.11e [2] e o 3GPP LTE [3], entre outros.

Um dos grande destaques do sistema em questão é sua forma de lhe dar com a interferência intersimbólica (ISI - Inter-Symbol Interference) existente em uma transmissão que experimenta canais multipercurso. A forma como esse aspecto negativo é tratado trouxe vantagens em relação a um transmissão mono portadora. Por causa disso existe uma grande tendência em utilizá-lo nos padrões de tecnologias de comunicação sem fio vindouros. Dentre essas tecnologias, podemos destacar as que advém dos padrões WiMAX IEEE 802.11e e 3GPP LTE, os quais são tidos como possíveis tecnologias de quarta geração de comunicação móvel.

Apesar do seu grande potencial, o OFDM possui alguns pontos críticos, dentre eles podemos destacar a grande variação da amplitude de sua forma de onda, usualmente representada pela razão entre a potência de pico e a potência média: PAPR (Peak-to-Average Power Ratio) do sinal.

Este Capítulo traz uma introdução sobre OFDM assim como a explicação de seus pontos positivos como a robustez à canais multipercurso, o que permite altas taxas de transmissão. Além disso, alguns aspectos da camada física do WiMAX são detalhados com a finalidade de 
exemplificar um padrão de tecnologia que utiliza OFDM como sua técnica de transmissão. Outro foco do Capítulo são os contratempos que o sistema de transmissão possui, mais especificamente, os altos valores de PAPR. Logo, é explicado o motivo de seu acontecimento bem como é feita uma análise da sua presença em sinais OFDM.

\section{$2.2 \quad$ OFDM}

Geralmente, as transmissões móveis experimentam canais multipercursos, ou seja, canais onde o sinal experimenta reflexões e onde a existência de uma transmissão direta é rara. Esses canais podem ser caracterizados por sua seletividade em frequência, ou melhor, a reposta do canal sofre grande variação em função da frequência do sinal. Um exemplo de tal canal é mostrado na Figura 2.1.

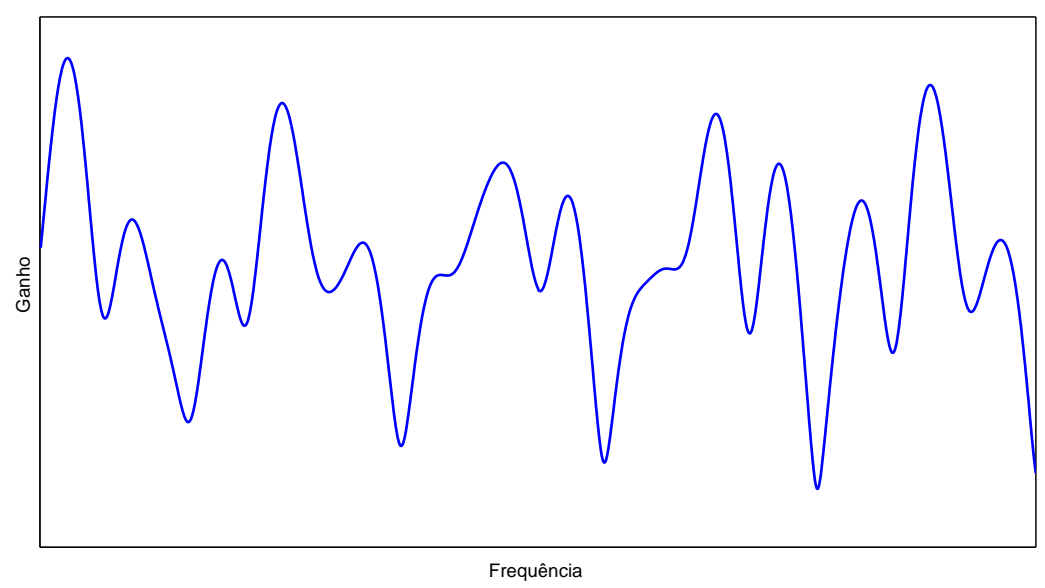

Figura 2.1: Canal seletivo em frequência

Portanto, um sinal transmitido em uma única portadora de banda larga irá experimentar diferentes ganhos de acordo com a frequência, o que dificultará a recepção, pois a necessidade de um equalizador complexo é evidente. Logo, é perceptível que a recepção de um sinal de banda estreita, que experimenta resposta pouco variável de um canal, é bem mais simples.

Uma das idéias do OFDM para mitigar o efeito de um canal multipercurso é dividir o sinal a ser transmitido em $N$ subportadoras ortogonais entre si de modo que cada uma delas experimente uma resposta plana do canal, ou seja, que cada subportadora experimente um canal coerente em frequência. Além disso, cada subportadora será responsável por transmitir um sinal a uma baixa taxa de transmissão, assim o efeito do espalhamento temporal (delay spread) do sinal decresce, visto que ao se aumentar a duração de um símbolo, a ISI diminui. Isso ocorre, pois quanto maior a duração do símbolo em relação ao espalhamento temporal do canal, menor é a ISI. Nota-se, portanto, que para um sistema com uma única portadora de banda larga, a sua taxa de transmissão é limitada pela dispersão 
temporal do canal caso se deseje uma recepçao livre de interferência intersimbólica[4].

Ainda com a finalidade de se eliminar ISI, é adicionado ao símbolo OFDM um intervalo de guarda de modo que parte do símbolo que foi espalhado temporalmente seja recebida nele. Quanto maior o espalhamento temporal do canal, maior deve ser o tempo de guarda.

A utilização do intervalo de guarda sem a presença de um sinal nem sempre é vantajosa, uma vez que pode não haver ortogonalidade entre as subportadoras caso elas experimentem espalhamentos temporais diferentes. Nota-se, então, a interferência entre subportadoras (ICI - Inter-Carrier Interference). Apesar disso, encontra-se aplicações dessa situação como, por exemplo, na TV digital. No entanto, a complexidade do receptor se torna maior.

Consequentemente, com a finalidade de evitar a interferência entre as portadoras, o intervalo de guarda é composto por uma extensão cíclica do símbolo, ou seja, uma parte final de um símbolo é adicionada ao seu início. Por causa disso, fala-se que um símbolo OFDM possui um prefixo cíclico. Deve-se ter em mente que com a inserção de um intervalo de guarda ou de um prefixo cíclico, a taxa de transmissão diminui, uma vez que no intervalo em questão não são enviados dados úteis.

Além disso, com a adição do prefixo cíclico, é possível fingir uma convolução circular do sinal com o canal, o que no domínio da DFT se torna uma multiplicação. Portanto, o equalizador do sistema em questão precisa apenas corrigir a amplitude e fase de cada subportadora de acordo com a resposta do canal, o que pode ser feito por uma simples multiplicação por um número complexo. Nota-se, então, que um equalizador de apenas um tap é suficiente.

Além disso, apesar da divisão do sinal a ser transmitido em diversas subportadoras que possuem menor taxa de transmissão, um sistema OFDM com várias subportadoras de banda estreita e com uma escolha de técnica de modulação e codificação eficiente bem como inteligente alocação de potência para cada subportadora atinge taxas de transmissões próximas à capacidade de Shannon [5].

É interessante ressaltar que nesse sistema é permitido que cada subportadora utilize uma técnica de modulação distinta, ou seja, caso a resposta do canal para determinada subportadora seja boa, pode-se utilizar um tipo de modulação que possua alta eficiência espectral. No entanto, caso a resposta do canal para uma subportadora seja ruim, o tipo de modulação utilizado deve ser aquele que tenha menor probabilidade de erro apesar de possuir baixa eficiência espectral.

Um transmissor multiportadora é evidenciado na Figura 2.2.

Primeiramente, o sinal analógico a ser transmitido é digitalizado, ou seja, transformado em bits. Em seguida, esses bits são divididos em blocos, onde um desses blocos é representado por um vetor denotado por $a_{n}$. Em seguida, mapeia-se essa sequência de bits em palavras m-árias $x_{k}$ e cada uma dessas palavras é destinada a uma das $N$ subportadoras. 


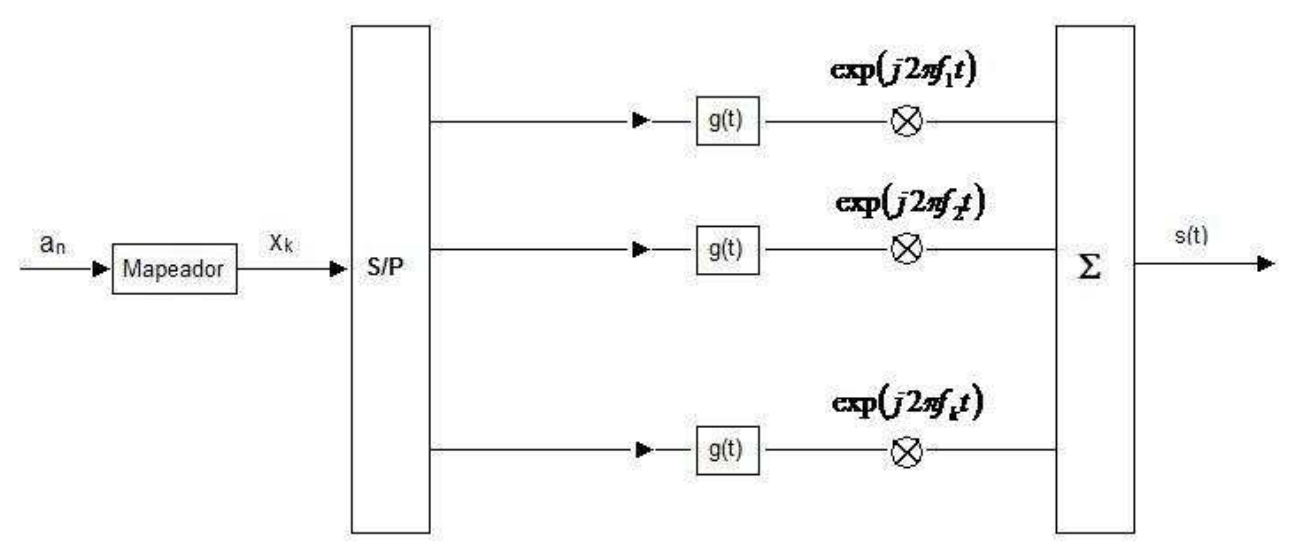

Figura 2.2: Transmissor OFDM

Há, então, uma conversão série-paralelo. Cada palavra ou símbolo é responsável por modular um sinal $g(t)$, que é um pulso que satisfaz o teorema de Nyquist. Além disso, esse sinal está em banda base e possui duração $T_{d}$, que é o intervalo de amostragem na saída da IFFT. Nota-se então que a duração de um símbolo OFDM é dada por

$$
T_{s}=N * T_{d},
$$

Logo após, o sinal será deslocado na freqência como resultado de uma multiplicação por $\exp \left(j 2 \pi f_{k} t\right)$, onde $f_{k}$ é a posição em frequência da $k$-ésima subportadora e para satisfazer o princípio da ortogonalidade é dado por

$$
f_{k}=\frac{k}{T_{s}}, k=0,1, \ldots, N-1
$$

Logo, o n-ésimo símbolo OFDM no tempo tem sua representação em banda base dada por

$$
s_{n}(t)=\sum_{k=1}^{N-1} x_{k, n} e^{j 2 \pi f_{k} t},
$$

onde $x_{k, n}$ é o símbolo mapeado na $k$-ésima portadora $f_{k}$.

A Figura 2.2 ilustra a presença de $N$ osciladores que possuem a finalidade de deslocar o sinal presente em cada subportadora na frequência. No entanto, ao se analizar a equação 2.3, nota-se que esse sinal pode ser constituído com a utilização de uma operação de DFT (Discrete Fourier Transform - Transformada Discreta de Fourier). Por causa disso, não existe a necessidade de vários osciladores e, computacionalmente, a transmissão do sinal se torna bem mais rápida. Para se alcançar maior eficiência, a DFT é feita ao se utilizar os algoritmos da FFT (Fast Fourier Transform - Transformada Rápida de Fourier) e da IFFT (Inverse Fast Fourier Transform - Transformada Rápida de Fourier Inversa). Aquele 
é utilizado na recepção para se fazer uma conversão serial - paralelo e este na transmissão, onde é necessária uma conversão paralelo - serial.

Ainda ao observá-la, é possível notar um dos motivos da robustez em relação à ISI, visto que os dados iniciais $a_{i}$ são divididos nas $N$ subportadoras e passam a ter duração de símbolo $N$ vezes maior.

Resumidamente, então, em uma transmissão OFDM os bits são destinados a cada uma das subportadoras e modulados de acordo com a técnica de modulação escolhida. Logo em seguida, é feita uma conversão parelelo-serial por meio da IFFT e o prefixo cíclico é inserido. Assim, o sinal OFDM está pronto para ser amplificado, situação que será analisada no Capítulo 3. Na recepção, o prefixo cíclico é retirado, uma conversão paralelo-serial é realizada por meio da FFT e então é realizada a demodulação para que os bits sejam recebidos.

A Figura 2.3 mostra um sinal OFDM na frequência. Nota-se que há a superposição espectral das diversas subportadoras. No entanto, como elas são ortogonais entre si, é possível separar a informação de cada uma delas com a utilização de um filtro casado adequado. Portanto, comprova-se o fato de uma multiplexação ortogonal por divisão de frequência.

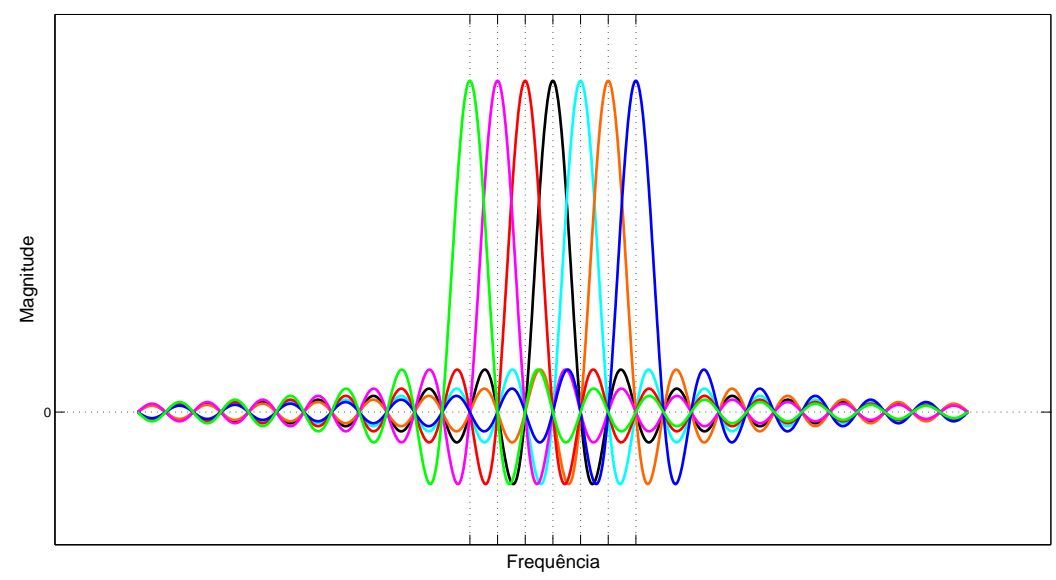

Figura 2.3: Sinal OFDM na frequência

Até agora foram citados alguns dos motivos pelos quais o OFDM se destaca como uma técnica de transmissão. Entretanto, não se deve ignorar suas imperfeições ou desvantagens. Abaixo, novamente são listadas as suas vantagens e são listadas, também, as suas desvantagens.

Vantagens:

1. Baixa complexidade de implementação devido às operações realizadas com a IFFT 
2. Robustez em relação a canais seletivos em frequência e a dispersão temporal, o que torna mais simples o equalizador a ser utilizado

3. Taxas de transmissão próximas à capacidade de Shannon ao se utilizar um grande número de subportadoras de banda estreita

4. Os dados de cada subportadora podem ser codificados e modulados independentemente se baseando nas condições de canal experimentadas pela subportadora. Consequentemente, a eficiência espectral aumenta.

5. Alocação de diversos usuários ao destinar a eles diferentes grupos de subportadoras, ou melhor, a possibilidade da utilização de OFDMA (Orthogonal Frequency Division Multiple Access - Múltiplo Acesso por Divisão em Frequências Ortogonais)

Desvantagens:

1. Perda de potência e eficiência espectral devido à inserção do prefixo cíclico.

2. Sensibilidade às não linearidades introduzidas pelo amplificador. Para tal caso ou se opera com baixa eficiência de potência ou sofre com o aumento da BER (Bit Error Rate - Taxa de Erro de Bit) e da radiação fora de banda do sistema, degradando o desempenho do sistema.

3. Sensibilidade ao desvio de frequência. Se ocorre desvio de frequência na entrada do demodulador, a BER cresce drasticamente, uma vez que ocorre ICI. Tal imperfeição pode ser introduzida pelo canal, o que é consequência do espalhamento Doppler, ou pode ser consequência da falta de sincronismo entre os osciladores das portadoras na transmissão e recepção, que pode ser evitado com maior precisão no ajuste das frequências.

4. Sensibilidade à resolução e faixa dinâmica dos conversores digital-analógico $(\mathrm{D} / \mathrm{A})$ e analógico-digital (A/D). Isso é consequência da elevada variação da amplitude da forma de onda de um sinal OFDM.

5. Ruído de fase introduzido pelos osciladores da transmissão e recepção.

Nota-se, portanto, que a técnica de transmissão em questão possui diversas desvantagens. No entanto, a sensibilidade às não linearidades do amplificador e ao desvio de frequência são tidas como as principais [5]. 


\subsection{WiMAX}

O sistema de comunicação sem fio WiMAX, que é regido pelo padrão IEEE 802.16, como já foi dito utiliza a técnica de transmissão OFDM em sua composição. Pode-se dizer, então, que sua camada física tem como base essa técnica, que proporciona altas taxas de transmissão, robustez contra canal seletivo em frequência e também é empregada em outras tecnologias.

A tecnologia em questão possui duas variantes: uma fixa e outra móvel, que possuem uma pequena diferença na constituição de sua camada física. A diferença básica consiste no fato de que aquela utiliza a técnica OFDM com 256 portadoras e essa utiliza OFDMA com número de portadoras variáveis entre 128 a 2048. A Tabela 2.1 mostra alguns dos parâmetros do OFDM utilizados na tecnologia em questão.

Tabela 2.1: Parâmetros do OFDM utilizados no WiMAX

\begin{tabular}{c|c|c|}
\hline Parâmetros & WiMAX Fixo & WiMAX Móvel \\
\hline FFT & 256 & $128,512,1024,2048$ \\
Largura de Banda $(\mathrm{MHz})$ & 3.5 & $1.25,5,10,20$ \\
Espaçamento entre subportadoras $(\mathrm{KHz})$ & 15.625 & 10.94 \\
Prefixo Cíclico & $1 / 32,1 / 16,1 / 8,1 / 4$ & $1 / 32,1 / 16,1 / 8,1 / 4$ \\
\hline
\end{tabular}

Como pode ser visto, o WiMAX fixo possibilita apenas a operação do OFDM com apenas um número de subportadoras: 256. Consequentemente, suas características se tornam mais fixas em relação ao WiMAX móvel, que possui quatro possibilidades para o número de portadoras a ser utilizado. Uma vez que o trabalho é focado em esquemas de transmissão móveis sem fio, será dado maior destaque ao WiMAX móvel.

Como consequência de possuir tamanhos variáveis para a FFT e manter o espaçamento entre as subportadoras fixo, o WiMAX móvel também possui quatro possibilidades de largura de banda, que variam de acordo com o tamanho da FFT, tornando-se, assim, mais flexível.

Outro aspecto interessante do WiMAX móvel está no fato de que o seu quadro pode ser dividido em regiões para diferentes usuários devido à utilização de OFDMA. Desse modo, caso um usuário necessite de uma grande quantidade de dados, pode-se designar a ela uma maior região dentro de um quadro.

Deve-se ressaltar, também, a existência de esquemas de permutação para o quadro, que nada mais são que modos de embaralhamento das subportadoras. A finalidade de tal permutação é conseguir melhor desempenho em canais seletivos em frequência. Alguns dos modos previstos são os modos de permutação AMC (Adaptative Modulation and Coding), PUSC (Partial Usage of SubChannels), FUSC(Full Usage of SubChannels) e TUSC (Tile 
Usage of SubChannels), que são detalhados em [2, 6].

Em relação às modulações utilizadas, existe a possibilidade de utilização de QPSK, 16 QAM e 64 QAM. A técnica de modulação BPSK só utilizada para canais de controle, uma vez que esses necessitam de alta confiabilidade em sua transmissão. Já em relação à codificação de canal, pode-se optar por utilizar codificação convolucional ou codificação turbo.

Além disso, com o intuito de melhorar o desempenho do sistema, pode-se utilizar outras técnicas que permitem ganhos em diferentes aspectos como: HARQ (Hybrid Automatic Repeat Request), que melhora o desempenho em relação à taxa de erro de bloco, e MIMO (Multiple Input Multiple Output), que consiste em um esquema de diversidade espacial.

\subsection{PAPR}

Ao se analisar novamente a Equação 2.3, nota-se que um símbolo OFDM é composto pela soma de $N$ subportadoras ortogonais, que possuem amplitudes determinadas pelos símbolos modulados em banda base. Esse sinal é composto por amostras que possuem tanto parte real como parte imaginária, que podem ser encaradas como variáveis aleatórias estaticamente independente e igualmente distribuídas [7]. Logo, com base no Teorema do Limite Central, ao se utilizar um alto valor para $N$ as partes real e imaginária das amostras temporais de um sinal OFDM pode ser modeladas por variáveis aleatórias Gaussianas com média zero e variância $\sigma^{2}$ que, por definição, é a potência média do sinal. Além disso, sendo as partes real e imaginária das amostras temporais modeladas por variáveis aleatórias Gaussianas, o envelope de tal sinal segue uma distribuição de Rayleigh [7].

A Figura 2.4 mostra que com o aumento de $N$, observa-se uma tendência a uma distribuição Gaussiana para a parte real das amostras de um sinal.

Desse modo, a maior parte do sinal possuirá baixa magnitude e haverá a ocorrência de alguns valores de magnitude muito altos. A Figura 2.5 ilustra um sinal OFDM no tempo onde é possível perceber a ocorrência de alguns picos de magnitude.

Usualmente, essa grande variação de amplitude de um sinal OFDM é mensurada pela razão entre a potência de pico e a potência média (PAPR) do sinal. Ela é definida para um símbolo com duração $T_{s}$ por:

$$
\operatorname{PAPR}(s(t))=\frac{\max _{0 \leq t \leq T_{s}}|s(t)|^{2}}{E\left[\frac{1}{T_{s}} \int_{0}^{T_{s}}|s(t)|^{2} d t\right]}
$$

Para efeitos de simulação computacional, utiliza-se a definição discreta de PAPR, ou melhor, a razão pico-média PAR (Peak to Average Ratio), que é dada por 


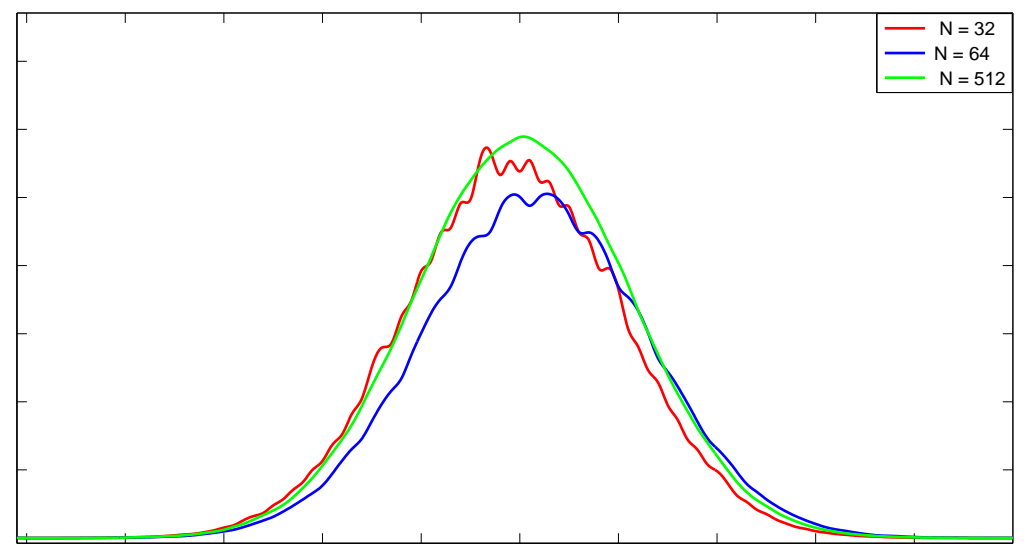

Figura 2.4: Distribuição estatística da parte real das amostras de um sinal OFDM ao variar $N$.

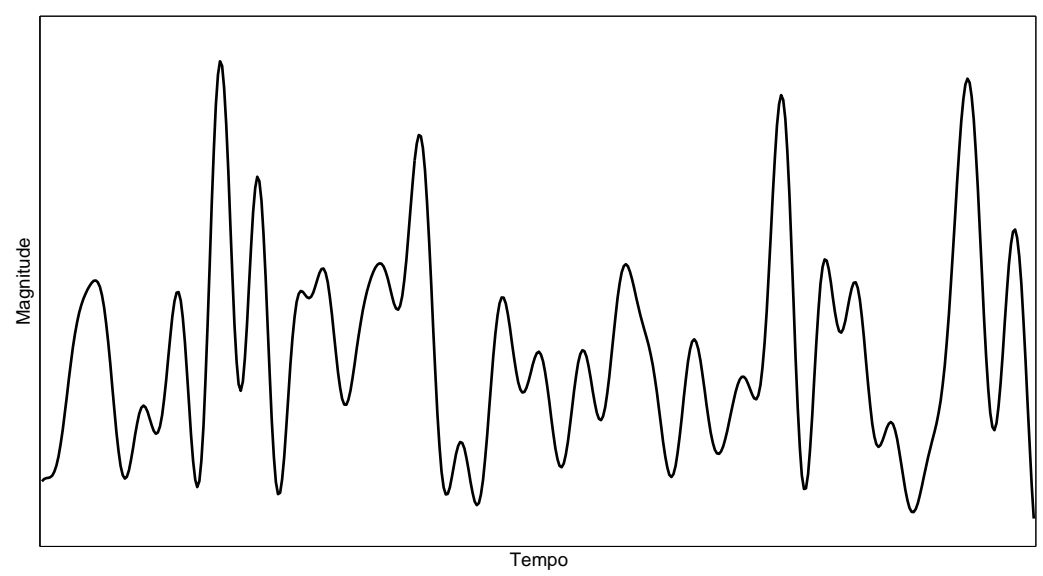

Figura 2.5: Sinal OFDM no tempo

$$
P A R(s)=\frac{\max _{i}|s(i)|^{2}}{E\left[\frac{1}{K}\|s(n)\|^{2}\right]},
$$

onde $x[n]$ são as amostras temporais de um símbolo OFDM e $K$ é a quantidade de amostras que formam um símbolo no tempo.

Deve-se ressaltar que geralmente $\operatorname{PAPR}(s) \geq P A R(s)$, uma vez que ao executar a superamostragem do sinal, podem surgir picos maiores que os já existentes. Portanto, ao se realizar uma análise em tempo discreto, serão encontrados valores mais otimistas para tal métrica e a análise do desempenho do sistema será prejudicada.

O valor de PAPR possui um limite que ocorre quando todos os símbolos possuem a mesma fase ao serem somados, o que resulta em uma soma construtiva [8]. No entanto, a ocorrência desse valor limite é extremamente rara e sua probabilidade de ocorrência se 
torna disprezível quando o valor de $N$ aumenta [9]. Portanto, não é vantajoso se ter como parâmetro de caracterização de PAPR de um sinal OFDM tal valor. Como consequência, uma análise da distribuição estatítisca da métrica em questão é comumente utilizada e tem sido bastante investigada [7, 10, 11].

Comumente, a CDF (Cumulative Distribution Function - Função de Densidade Acumulada) de PAPR de um sinal OFDM é utilizada para analisar a ocorrência de altos picos no sinal. Portanto, é possível mensurar a probabilidade de ocorrência de valores de PAPR menores que determinado valor.

Primeiramente, como já foi dito, deve-se ter em mente que ao se trabalhar em tempo discreto os resultados serão otimistas em relação à realidade. Para se produzir algo não tão longe da realidade, deve-se superamostrar o sinal. Desse modo, o sinal pode passar a ter picos maiores do que tinha anteriormente, o que irá alterar seus valores de PAPR. A Figura 2.6 mostra a CDF de PAPR de um sinal OFDM com 512 subportadoras moduladas em QPSK. Nela é possível notar a diferença entre um sinal superamostrado a uma taxa de quatro vezes e um sinal não superamostrado. Aquele sinal possui maior probabilidade de ocorrência de altos valores de PAPR em relação a esse. Logo, nota-se a importância da superamostragem do sinal na análise do sistema baseada em tal métrica. Portanto, nota-se o que foi dito anteriormente: os resultados em tempo discreto são otimistas em relação ao resultados em tempo contínuo.

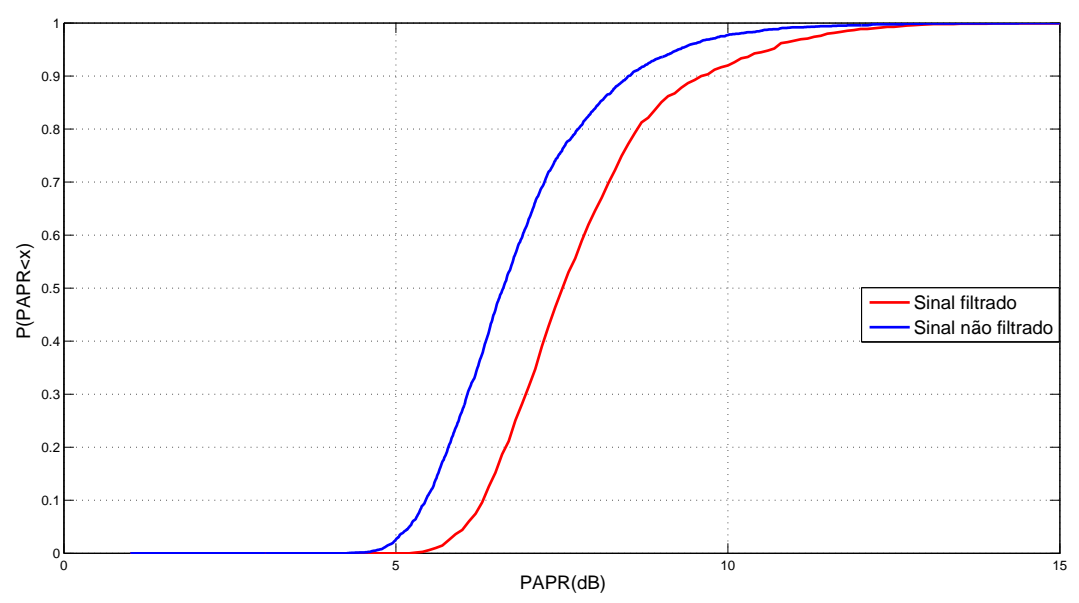

Figura 2.6: CDF de PAPR de sinais OFDM filtrado e não filtrado

Além disso, quanto maior o valor de $N$ (número de subportadoras utilizadas na transmissão), maior é a probabilidade de ocorrência de altos valores de PAPR [8]. Isso ocorre, pois ao aumentar o número de amostras, o espaço amostral se torna maior. Portanto, a probabilidade de ocorrência de um alto valor de pico também cresce. A Figura 2.7 ilustra justamente essa situação, onde novamente foi utilizada a modulação QPSK com uma taxa de superamostragem de quatro. 


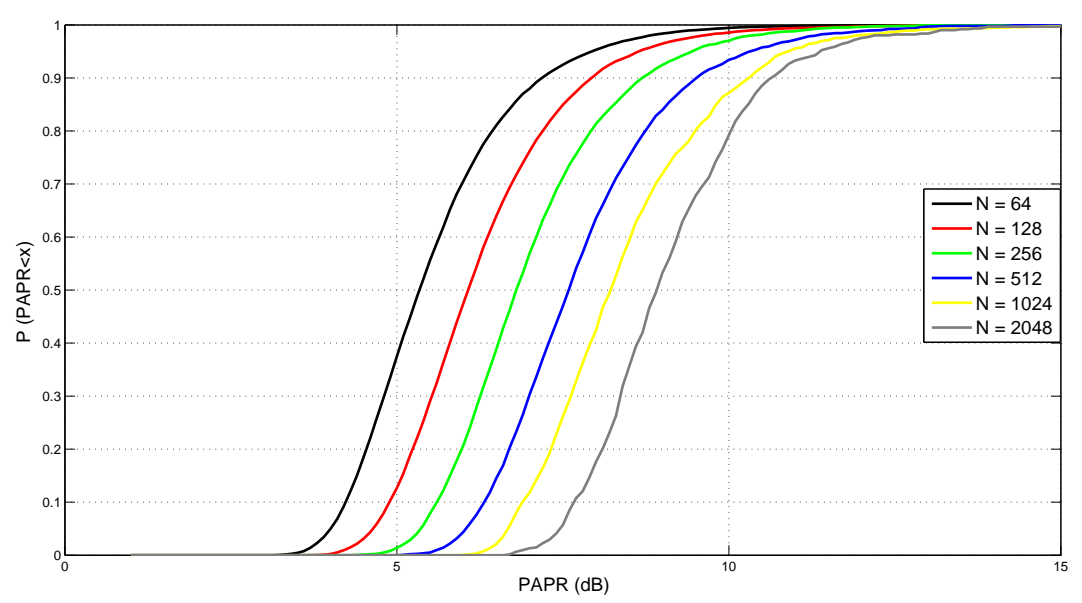

Figura 2.7: CDF de PAPR de sinais OFDM com diferentes números de subportadoras

Já a Figura 2.8 evidencia a CDF de PAPR de um sinal OFDM ao se alterar o técnica de modulação. Nota-se que não há diferença entre a utilização de QPSK, 16 QAM e 64 QAM. No entanto, quando se utiliza a modulação BPSK (Binary Phase Shift Keying Chaveamento binário por deslocamento de fase), existe menor probabilidade de se encontrar altos valores de PAPR do que ao se utilizar as outras modulações. É válido ressaltar que foram utilizadas 512 subportadoras na transmissão e o sinal foi superamostrado em quatro vezes.

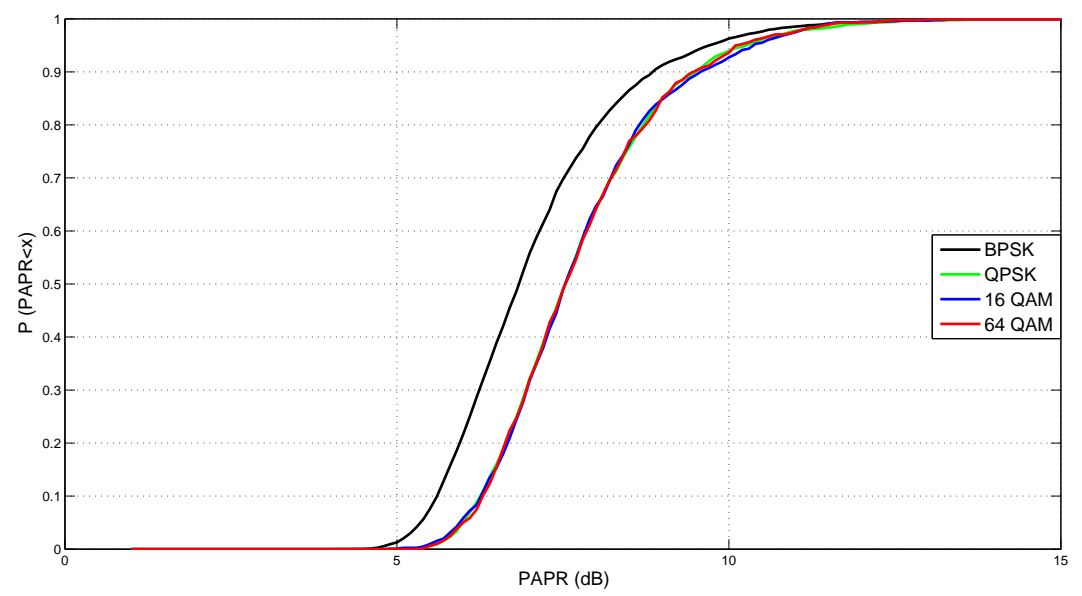

Figura 2.8: CDF de PAPR de sinais OFDM com diferentes modulações 


\title{
Capítulo 3
}

\section{OFDM com amplificação não linear}

\author{
Neste Capítulo são apresentados e analisados \\ três tipos de amplificadores. Ademais, com a \\ finalidade de analisar um sistema OFDM na \\ presença desses dispositivos são introduzidas \\ algumas figuras de mérito como Degradação \\ Total e ACPR.
}

\subsection{Introdução}

Em um sistema de transmissão OFDM, a presença de um amplificador de potência é indispensável. Consequentemente, na tentativa de simular tal sistema, a modelagem desses dispositivos se torna extremamente necessária, uma vez que ele afeta o seu desempenho. Como poderá ser visto, tal dispositivo não possui um comportamento linear, o que seria extramamente vantajoso para o sistema. O seu comportamento é não linear, podendo alterar tanto a magnitude do sinal quanto sua fase.

Portanto, neste Capítulo serão introduzidos três tipos de modelos de amplificadores, dois deles causam apenas distorção de amplitude e o outro provoca tanto distorção de amplitude quanto distorção de fase. Essas características serão evidenciadas tanto em forma de equação quanto em forma gráfica, ao se representar a função de transferência de cada dispositivo.

Além de se conseguir modelar a atuação de um amplificador em um sistema de transmissão, deve-se conseguir também analisar o desempenho do sistema na presença desse dispositivo de amplificação. Para isso, existem algumas figuras de mérito capazes de realizar tal tarefa. Consequentemente, algumas delas serão explicadas aqui com a finalidade de serem utilizadas nas análises posteriores dos sistemas simulados. 


\subsection{Amplificadores}

Logo após a operação de IFFT na transmissão de um sinal OFDM, ele é submetido à entrada de um amplificador de potência, que possui características não lineares. O sinal na entrada do amplificador pode ser representado pela seguinte notação

$$
x(t)=A(t) \cos \left[\omega_{0} t+\psi(t)\right]=R e\left[x_{b}(t) e^{j \omega_{0} t}\right],
$$

onde $x_{b}(t)=A(t) e^{j \Psi(t)}$ é o sinal de entrada em banda base com $A(t)$ e $\Psi(t)$ sendo o envelope e a fase do sinal modulado, respectivamente.

O sinal na saída do amplificador será dado por

$$
y(t)=G[A(t)] \cos \left\{\omega_{0} t+\psi(t)+\Phi[A(t)]\right\}=\operatorname{Re}\left[y_{b}(t) e^{j \omega_{0} t}\right],
$$

onde $y_{b}(t)=G[A(t)] e^{j\{\Psi(t)+\Phi[A(t)]\}}$ e $G[A(t)]$ e $\Phi[A(t)]$ representam, respectivamente, a conversão AM/AM e AM/PM causada pelo amplificador não linear.

Portanto, o efeito provocado pelo amplificador não linear pode ser representado em banda base pela seguinte relação

$$
x_{b}(t)=A(t) e^{j \Psi(t) \stackrel{A m p}{\rightarrow}} y_{b}(t)=G[A(t)] e^{j\{\Psi(t)+\Phi[A(t)]\}},
$$

Logo, conclui-se que o efeito causado pelo amplificador é uma alteração na amplitude do sinal segundo uma função $G[A]$ e uma alteração na fase do sinal modelada por $\Phi[A(t)]$. É interessante ressaltar que ambas alterações são em função da amplitude do sinal e não são lineares. Logo, um sistema OFDM será bastante sensível a esse fato, uma vez que possui grande variação em sua amplitude como mostrado na Figura 2.5.

Foram utilizados três modelos de amplificadores não lineares no trabalho, são eles

1. Um amplificador TWT (Travelling Wave Tube - Tube de Onda Viajante) com forte conversão AM/PM seguindo o modelo de Saleh [12]

2. Um amplificador não linear de estado sólido sem conversão AM/PM [13]

3. Um amplificador idealizado limitador de envelope

Os modelos que representam amplificadore TWT podem ser representados com apenas quatro parâmetros e suas funções de conversão são modeladas da seguinte forma [12]

$$
G(A)=\frac{\alpha_{G} A}{1+\beta_{G} A^{2}},
$$




$$
\Phi(A)=\frac{\alpha_{\Phi} A^{2}}{1+\beta_{\Phi} A^{2}},
$$

em que $\alpha_{G}=2, \beta_{G}=1, \alpha_{\Phi}=\pi / 3$ e $\beta_{\Phi}=1$ para o modelo de Saleh utilizado no trabalho.

A ilustração das características das conversões AM/AM e AM/PM do amplificador em questão podem ser analisadas na Figura 3.1.

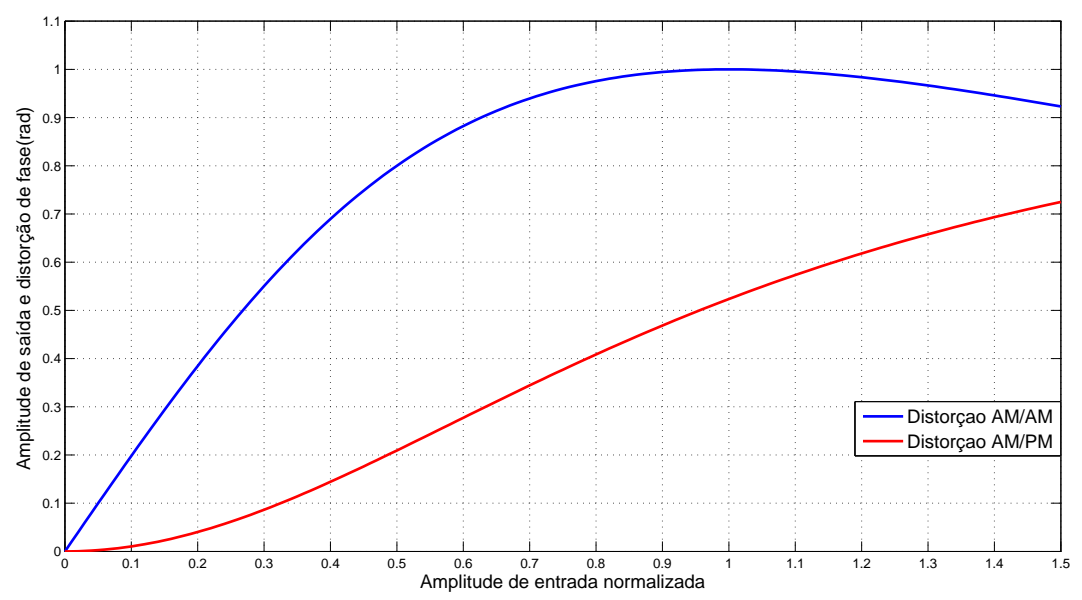

Figura 3.1: Características das conversões AM/AM e AM/PM para o amplificador modelo de Saleh

O amplificador de estado sólido segue o modelo de Rapp [13]. A conversão AM/PM é desprezada para esse modelo e a sua converão AM/AM é dada por

$$
G(A)=\frac{v A}{\left[1+\left(\frac{v A}{A_{0}}\right)^{2 p}\right]^{1 / 2 p}},
$$

em que $A_{0}$ é a amplitude máxima, $\nu$ é o ganho de pequeno sinal e $p$ é o fator de suavização para o modelo de Rapp. Tanto a amplitude máxima quanto o ganho de pequeno sinal foram normalizados para uma unidade. Já o fator de suavização deve obedecer a seguinte relação: $2 \leq p \leq 3$

O amplificador idealizado limitador de envelope também não possui conversão AM/PM e sua conversão AM/AM é dada por

$$
G(A)=\left\{\begin{array}{rrr}
\nu A_{0} & \text { se } & A>A_{0} \\
\nu A & \text { se } & A \leq A_{0}
\end{array} .\right.
$$

A Figura 3.2 evidencia a função de transferência de amplitude dos amplificadores modelo de Rapp e limitador de envelope, para os modelos de Rapp foram utilizados os valores de $p=2$ e $p=3$. É possível verificar que quanto maior é o valor de utilizado para $p$, mais suave é a transição da curva para a saturação. 


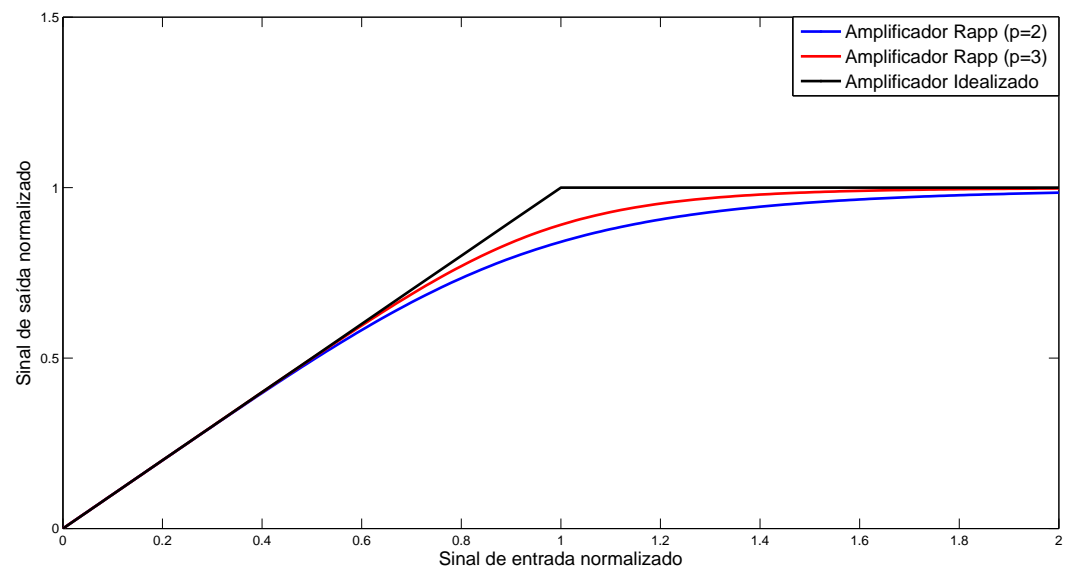

Figura 3.2: Função de Transferência dos Amplifificadores Rapp e limitador de envelope

Ao analisar a função de transferência de um amplificador, observa-se que não é possível aumentar a potência do sinal de entrada indefinidamente, visto que a região de saturação será atingida, o que acarretará em uma grande distorção do sinal. Logo, deve-se fazer um recuo na potência do sinal em relação à região de saturação imprimida pelo amplificador para que ele trabalhe perto de sua região linear. Portanto, em uma análise envolvendo amplificadores, a definição de backoff de potência se torna indispensável.

O termo backoff de potência, basicamente, expressa a diferença de potência existente entre a saturação do amplificador e a potência média do sinal. Existe uma definição tanto para o backoff de entrada (IBO - Input Backoff) quanto para o backoff de saída (OBO emphOutput Backoff) e são dadas por

$$
\begin{gathered}
I B O_{d B}=10 \log _{10}\left(\frac{P_{\text {sat }, \text { in }}}{P_{\text {in }}}\right) \\
O B O_{d B}=10 \log _{10}\left(\frac{P_{\text {sat }, \text { out }}}{P_{\text {out }}}\right),
\end{gathered}
$$

em que $P_{\text {in }}$ e $P_{\text {out }}$ são as potências médias de entrada e saída, respectivamente; e $P_{\text {sat,in }}$ e $P_{\text {sat,out }}$ são as potências de saturação de entrada e saída, respectivamente, que são obtidas da função de conversão AM/AM. Aqui, a $P_{\text {sat,in }}$ é definida como a potência de entrada que levaria o amplificador à $P_{\text {sat,out }}$ caso ele fosse linear.

A Figura 3.3 mostra a função de transferência de um amplificador não linear genérico e ao analisá-la é possível visualizar as definições dadas para o backoff.

As Figuras 3.4 e 3.5 ilustram a consequência na constelação de um sinal ao se trabalhar perto da saturação do amplificador. A primeira é para o caso em que se utiliza o amplificador de Saleh com $\mathrm{OBO}=6.18 \mathrm{~dB}$, onde é evidente que além de sofrer com a distorção de magnitude, o sinal sofre com uma distorção de fase. A segunda é para a situação em que 


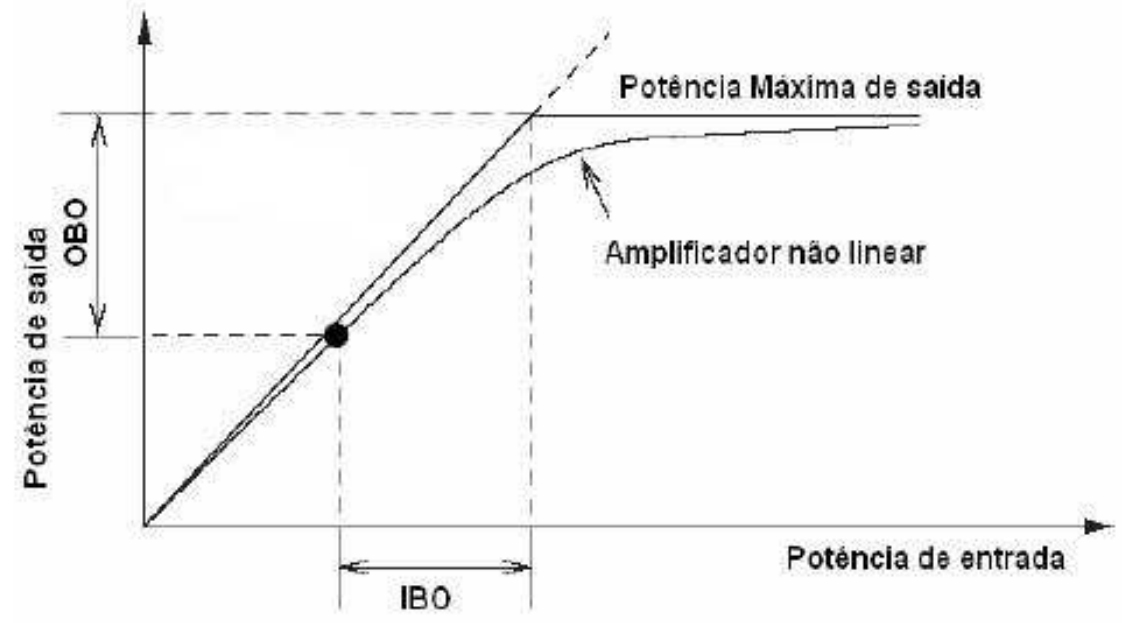

Ponto de operaçäo do Sinal

Figura 3.3: Função de Transferência de um Amplificador Não Linear Genérico se utiliza um amplificador Rapp com $p=3$ e $\mathrm{OBO}=4.81 \mathrm{~dB}$.

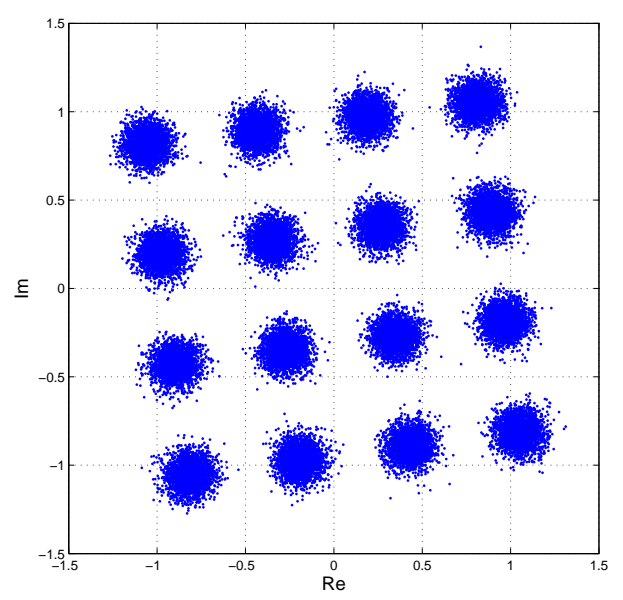

Figura 3.4: Constelação de um sinal após passar por um amplificador de Saleh.

Em ambos os casos ficam claras as consequências da não linearidade de um amplificador, consequência tal que é percebida na degradação da BER na recepção do sinal.

\subsection{Figuras de Mérito}

Já foi dito que em um sistema de transmissão OFDM, o efeito de uma amplificação não linear é um aspecto que deve ser considerado. Para tal consideração, há alguns parâmetros de análise que facilitam o projeto de um sistema com a finalidade de que ele possua um bom desempenho.

Além disso, já foi visto que um sinal OFDM possui uma grande variação de amplitude 


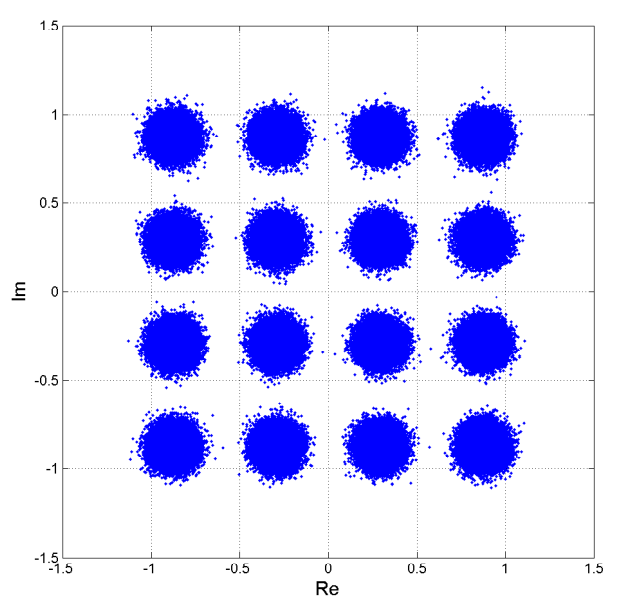

Figura 3.5: Constelação de um sinal após passar por um amplificador Rapp.

no tempo e que ela pode ser representada por uma métrica denominada PAPR, com a qual é realizada uma análise estatística com o intuito de se conhecer melhor o comportamento do sinal. Essa análise estatística é realizada com a CDF de PAPR em um sinal OFDM. Portanto, se um dos problemas do sinal em questão é sua grande variação de amplitude, caso isso seja diminuído, tem-se uma amenização do problema e, consequentemente, a PAPR do sinal também diminui.

Outro parâmetro utilizado na análise do sistema em questão é o recuo de potência realizado em relação à saturação do amplificador não linear utilizado, ou melhor, o backoff. Como já foi dito, esse recuo é feito para se trabalhar perto da região linear do amplificador, onde a distorção não linear causada é menor do que ao se trabalhar na saturação. Entretanto, ao se trabalhar longe da região de saturação, a eficiência de potência diminui, algo não desejável para um sistema de transmissão sem fio.

Logo, já possuímos alguns parâmetros que nos permitem realizar a análise de um sistema de comunicação sem fio que utiliza a técnica OFDM. No entanto, para um bom desempenho do sistema não é suficiente apenas reduzir a PAPR do sinal, deve-se garantir, também, o bom desempenho do sistema. Potanto, a análise do desempenho de um sistema OFDM quando se leva em consideração a presença de um amplificador não linear deve ser feita à sombra de três quesitos: a taxa de erro de bit (BER), o backoff utilizado e a radiação fora de banda causada.

A definição de backoff já foi citada. Entretanto, a definição do valor de backoff a ser utilizado não deve ser feita arbitrariamente. Ele deve ser estipulado de tal forma que

- seja o menor possível com a finalidade de minimizar a perda de eficiência de potência dada pelo fato de não se operar na saturação;

- a relação $E_{b} / N o$ necessária para garantir determinado valor de BER seja a menor 
possível

Essa solução de compromisso pode ser analisada com a ajuda de um figura de mérito denominada Degradação Total (DT) e definida por

$$
D T_{d B}=O B O_{d B}+\left[E b N o_{(O B O)}-E b N o_{(\text {linear })}\right]_{B E R}
$$

onde $E b N o_{(O B O)}$ e $E b N o_{(\text {linear })}$ são as relações de $E b / N o$ requeridas em dB para o amplificador não linear utilizado e para um amplificador ideal linear e $O B O_{d B}$ é o backoff de saída. Além disso, essa figura de mérito é mensurada para um determinado canal e para uma determinada BER.

Consequentemente, o valor de backoff a ser escolhido de forma que se tenha menor degradação de BER e maior eficiência de potência é aquele em que acarreta menor Degradação Total (DT) do sistema. Ele é, então, referido como backoff ótimo. Por causa disso, um sistema apresentará bom desempenho se possuir os valores mínimos de DT e backoff ótimo menores possíveis. Já um sistema que possuir seus valores mínimos altos, apresentará um mal desempenho.

Outro ponto que deve ser salientado é o fato da curva de DT possuir uma assíntota. Isso ocorre, uma vez que quanto maior o valor de backoff, mais próximo da faixa linear do amplificador o sinal está. Portanto, a degradação por conta da não linearidade do amplificador é baixa, o que acarreta em um desempenho próximo da situação linear, que é determinada pela assíntota.

A Figura 3.6 ilustra a consequência da utilização de um amplificador não linear á medida que a potência média do sinal se aproxima do ponto de saturação do amplificador, ou seja, quando o valor de backoff diminui. É com base nesse tipo de simulação que uma curva de Degradação Total como mostra a Figura 3.7 é gerada. Além disso, é importante ressaltar que essa curva deve ser gerada para um tipo de canal específico e para um determinado valor de BER. As simulações que geraram as duas figuras citadas anteriormente foram feitas para um canal AWGN (Additive White Gaussian Noise - Ruído Gaussiano Branco Aditivo) com um sinal OFDM que possui 512 subportadoras sendo 420 portadoras de dados e que é modulado em QPSK. Para a curva de DT foi utilizada BER $=10^{-4}$.

Além disso, uma análise no domínio na frequência também se torna indispensável, uma vez que os padrões de tecnologia sem fio estipulam máscaras de frequência para o sinal transmitido com a finalidade de não se observar grande interferência em bandas adjacentes.

Um primeiro quesito a ser analisado no domínio da frequência é a Densidade Espectral de Potência (PSD - Power Spectral Density) de um sinal. Na Figura 3.8 é possível comparar a DSP de dois sinais OFDM: um deles não é amplificado e o outro é amplificado por um amplificador modelo Rapp $(\mathrm{p}=3)$ utilizando $\mathrm{OBO}=3.09 \mathrm{~dB}$.

Além disso, existe uma figura de mérito que possibilita analisar a relação entre a potência contida na banda desejada $\left(P_{\text {inBand }}\right)$ e a potência que está fora dela $\left(P_{\text {outBand }}\right)$. Ela é 


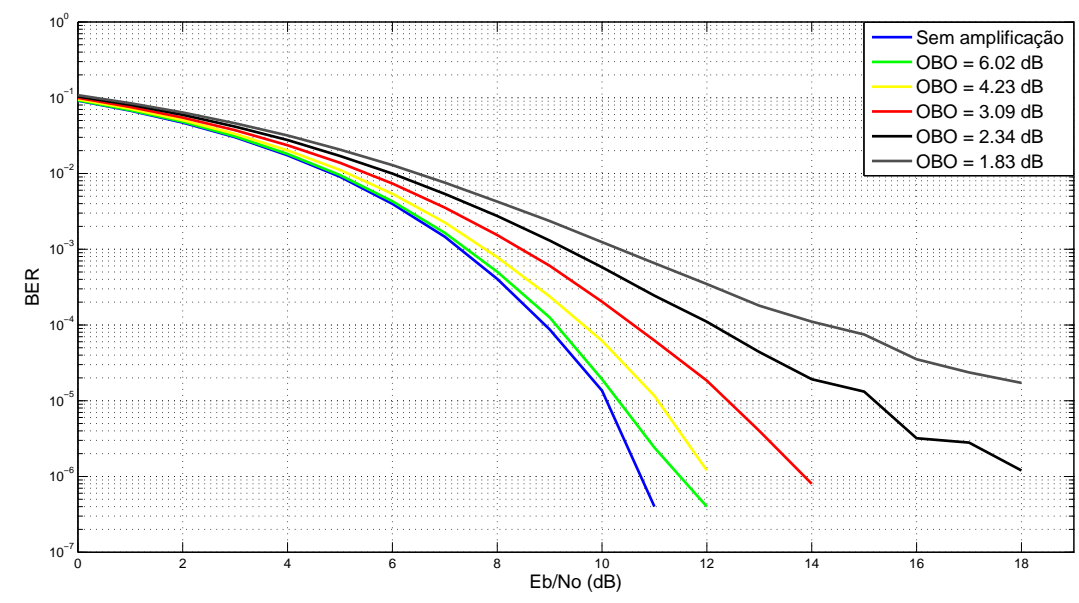

Figura 3.6: BER x EbNo para diferentes valores de OBO

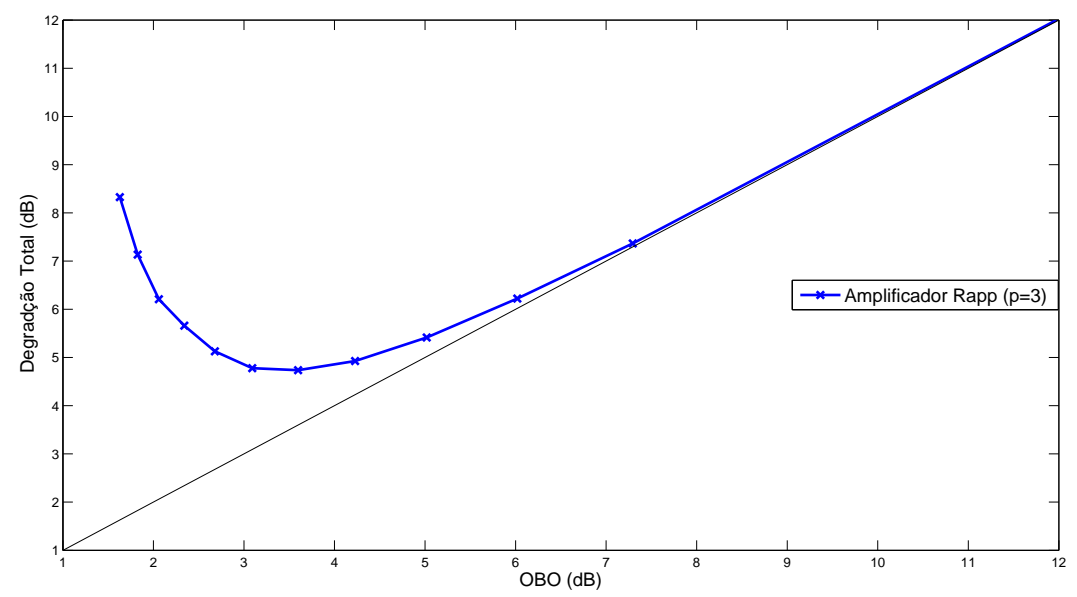

Figura 3.7: Degradação Total para um canal AWGN e $B E R=10^{-4}$

denominada ACPR (Ajacent Channel Power Ratio - Relação entre potências de canais adjacentes) e é definida por

$$
A C P R_{d B}=10 \log _{10}\left(\frac{P_{\text {inBand }}}{P_{\text {outBand }}}\right)
$$

A vantagem da análise utilizando ACPR é o fato de que ela pode ser mensurada em função do backoff, o que ficaria complicado para a PSD. A Figura 3.9 ilustra essa situação para um sinal OFDM, onde é perceptível que quanto maior o valor de $O B O$, maior a quantidade de sinal contido dentro da banda de interesse. Isso é consequência do fato de que quanto maior o valor de $O B O$, mais longe da saturação está o sinal, ou seja, mais linear é sua amplificação. 


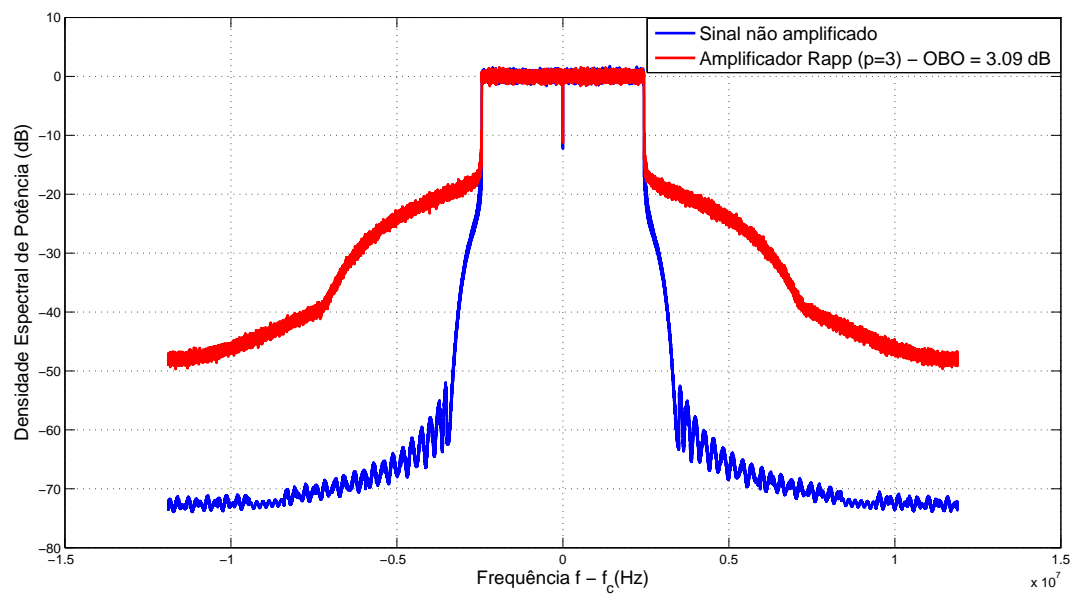

Figura 3.8: Densidade Espectral de Potência de sinais OFDM

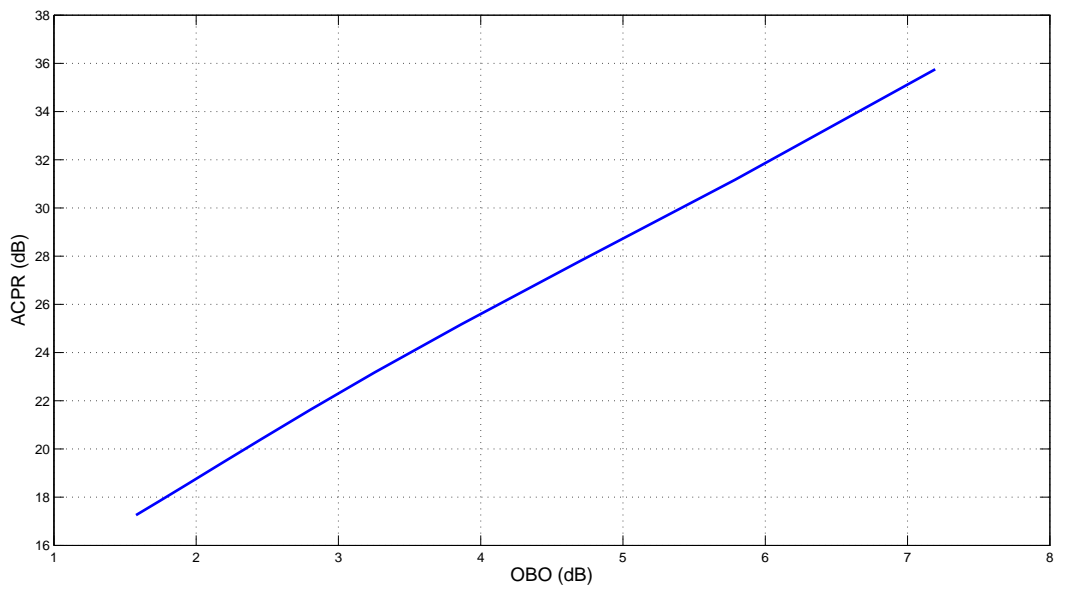

Figura 3.9: Variação da ACPR em função do OBO 


\section{Capítulo 4}

\section{Técnicas de mitigação de não linearidades em OFDM}

Neste Capítulo são apresentadas e detalhadas duas técnicas de redução de PAPR. São elas o clipping e o método de Jones.

\subsection{Introdução}

No Capítulo 2 foi mostrado que um sinal OFDM possui altos valores de PAPR devido a sua grande variação de amplitude. Já no Capítulo 3 foram mostradas as consequências dessa característica do sinal na presença de um amplificador de potência, que, por sua vez, possui comportamento não linear.

Portanto, para que os efeitos não lineares de um amplificador sejam amenizados, deve-se fazer um recuo de potência em relação à região de saturação do amplificador. Entretanto, ao realizar esse recuo, observa-se pouco aproveitamento de potência do dispositivo em questão, ou seja, tem-se baixa eficiência de potência. Consequentemente, ao se diminuir a PAPR do sinal, existe a probabilidade de se mitigar esse efeito indesejado.

Vários estudos vêm sendo feitos e várias técnicas têm sido propostas com a finalidade de amenizar a sensibilidade de um sinal OFDM às não linearidades de um amplificador ao diminuir seus valores de PAPR $[14,15,11,16,17,18,19,20]$. No entanto, grande parte das técnicas propostas e estudadas necessitam o envio de sinalização extra, como o método de sequências de transmissões parciais $[16,17]$ e o de mapeamento seletivo [18, 19].

Uma vez que algum método de redução de PAPR necessita o envio de sinalização extra, ele não é compatível com as normas de tecnologia de transmissão sem fio. Portanto, o foco do trabalho está em métodos que não possuam essa característica, como o clipping e o método de extensão ativa da constelação ou método de Jones [20]. 


\subsection{Método de clipping}

Uma maneira bem simples de reduzir a PAPR de um sinal se consiste em simplemesmente cortar o sinal caso ele exceda algum valor indesejado. Esse é o método de clipping, onde o sinal OFDM é basicamente cortado com o intuito de limitar o valor máximo que o sinal pode assumir, que será referido como $A_{c}$ (Amplitude de corte). É perceptível que o método em questão não necessita de sinalizações a mais.

As Figuras 4.1 e 4.2 mostram, respectivamente, um sinal OFDM no tempo e esse mesmo sinal após passar pelo processo de clipping.

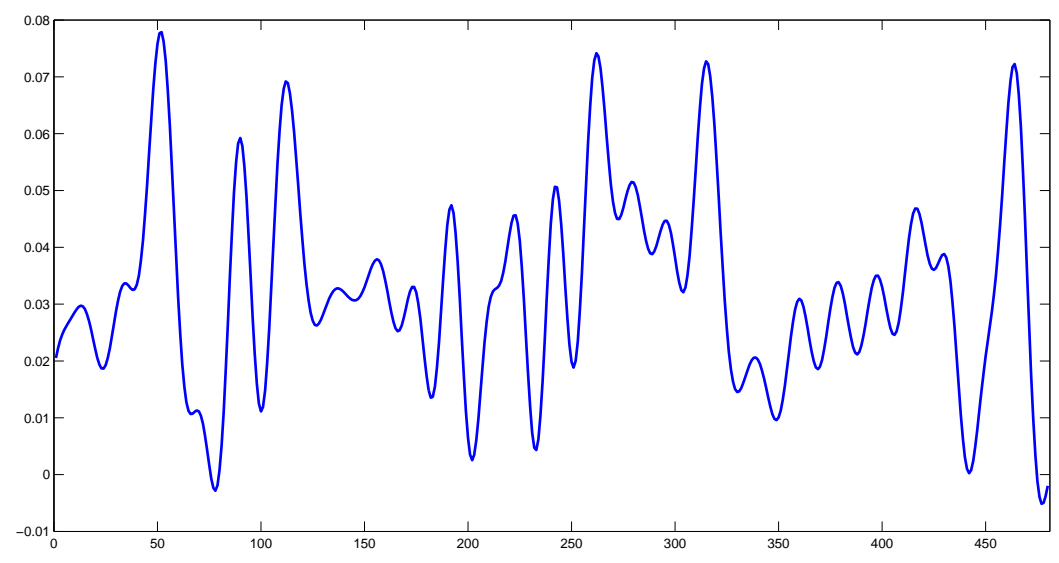

Figura 4.1: Sinal OFDM no tempo

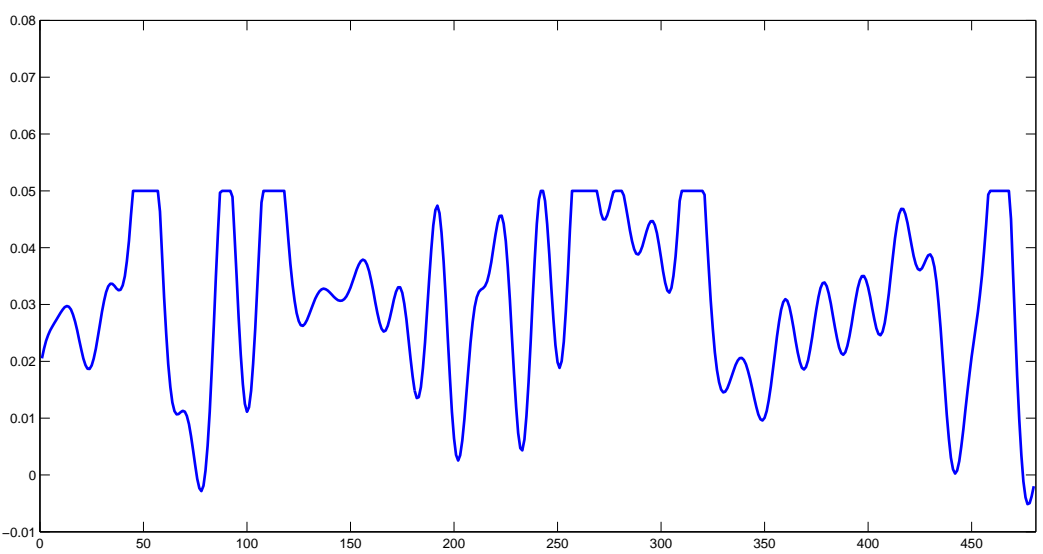

Figura 4.2: Sinal OFDM no tempo após clipping

Como pôde ser visto, o método em questão diminui a faixa dinâmica de amplitude de um sinal OFDM, o que resulta em redução de PAPR. No entanto, sua utilização intensifica a radiação fora de banda, uma vez que é, intrinsecamente, uma operação não linear. Logo, após sua aplicação deve-se realizar a filtragem do sinal com a finalidade de mantê-lo dentro de sua banda específica. 


\subsection{Método de Jones}

O método de extensão ativa da constelação [20] consiste, basicamente, na modificação da constelação do sinal sem sem que sua taxa de erro aumente. O efeito dessa modificação é a adição de senóides ou cossenóides em algumas frequências que podem acarretar no cancelamento de alguns picos do sinal, os quais são indesejados. A alteração da constelação não compromete o desempenho, uma vez que os pontos sinais modificados são projetados em uma região com maior margem para erro.

A Figura 4.3 mostra a constelação de um sinal com a modulação 16 QAM ao ser modificado pelo método em questão, onde é possível perceber que as regiões ótimas de decisão não são abandonadas.

Além disso, é interessante notar que a aplicação do método acarreta, entretanto, no aumento da potência do sinal. Todavia, esse aumento não é significativo quando comparado ao ganho trazido por ele [20].

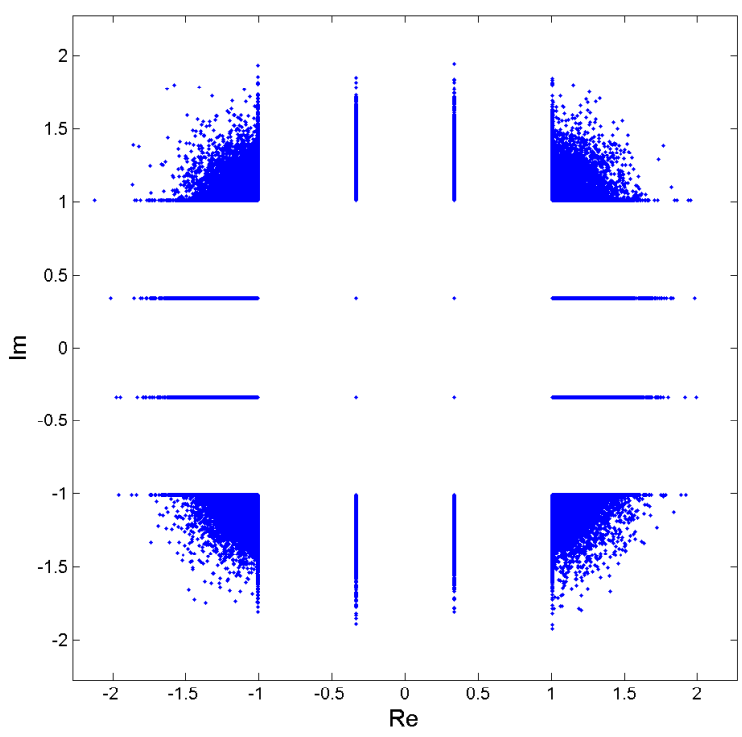

Figura 4.3: Constelação após aplicação do método de Jones para o 16 QAM

O algoritmo deve modificar apenas as subportadoras de dados, deixando inalteradas as subportadoras piloto e de guarda. Ele pode ser descrito pelos seguintes passos, que são executados símbolo a símbolo OFDM:

1. De acordo com os dados de entrada, designar os símbolos $X_{k}$ que serão mapeados em pontos sinais na constelação

2. Construir o símbolo OFDM no tempo via IFFT

3. Comparar a magnitude de todas as amostras com $L_{\max }$, o valor estipulado como máximo 
4. Para as amostras que excederam $L_{\text {max }}$, redimensioná-las, isto é, fazer $\tilde{x}=L_{\max } e^{j \theta_{n}}$, onde $x_{n}=\left|x_{n}\right| e^{j \theta_{n}}$

5. Obter novamente o sinal no domínio da freqüência via FFT

6. Restabelecer as portadoras piloto e de guarda. Restaurar os pontos interiores aos valores originais e projetar os pontos externos para as regiões de maior margem. Por exemplo, caso um símbolo esteja mapeado originalmente com valores real e complexo igual a 1 e após o passo anterior sua parte real se tornar 1.5 e a imaginária 0.5 , ele passará a se localizar no ponto com parte real igual a 1.5 e parte imaginária igual a 1.

7. Retornar ao passo 2 e executar o algoritmo até que nenhuma amostra temporal seja redimensionada ou que o número máximo de iterações seja atingido

Além das vantagens já citadas do método, percebe-se que seu algoritmo não possui grande complexidade e, como será visto, não são necessárias muitas iterações para que se chegue a um resultado satisfatório. Outra característica extremamente positiva consiste no fato de que sua aplicação não demanda sinalização adicional, ou nenhuma modificação nos receptores. Isso o torna aceitável pelas normas que definem tecnologias que empregam a transmissão OFDM em sua camada física.

É interessante ressaltar, também, que os únicos parâmetros ajustáveis do método são o número de iterações máximo e o valor de $L_{\max }$, os quais serão analisados no Capítulo 5 . Além disso, o método também pode ser aplicado quando se utiliza outras modulações, as Figuras 4.4 e 4.5 mostram a disposição da constelação de sinais modulados em QPSK e 64 QAM, respectivamente, após a aplicação do método. 


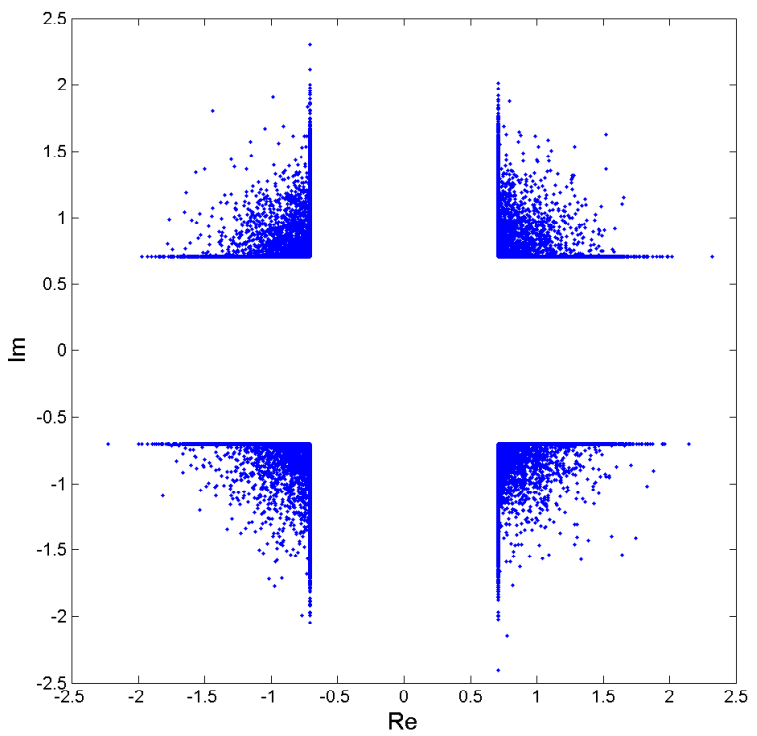

Figura 4.4: Constelação após aplicação do método de Jones para o QPSK

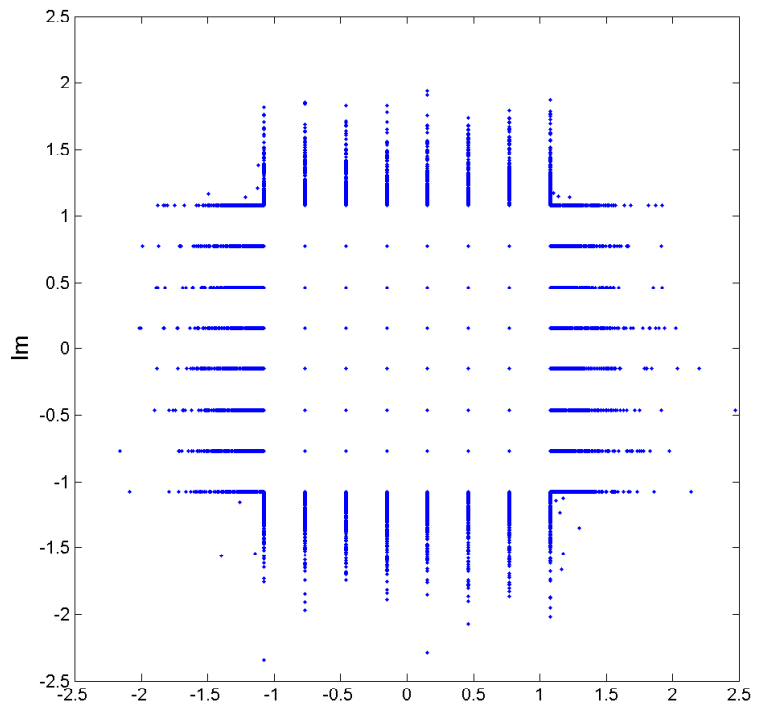

Figura 4.5: Constelação após aplicação do método de Jones para o 64 QAM 


\section{Capítulo 5}

\section{Resultados de Simulação}

Este Capítulo traz a análise do desempenho de um sistema OFDM genérico bem como de um sistema WiMAX móvel na presença dos amplificadores detalhados no Capítulo 3. Além disso, o desempenho dos métodos de redução de PAPR introduzidos no Capitulo 4 é analisado.

\subsection{Introdução}

No Capítulo 3 foram detalhadas algumas figuras de mérito que nos permitem analisar a operação de um sistema OFDM com a utilização de um amplificador não linear. Além disso, no mesmo capítulo foram detalhados três modelos de amplificadores a serem utilizados em tal sistema. Logo, neste Capítulo serão analisados os desempenhos dos amplificadores detalhados à sombra das figuras de mérito introduzidas. Essa análise foi realizada tanto para um sistema OFDM genérico quanto para um sistema WiMAX.

Para a simulação de um sistema WiMAX foi desenvolvido um simulador baseado no padrão IEEE 802.16e. Para tanto, as ferramentas detalhadas pelo padrão foram modeladas com o auxílio da ferramenta MatLab. Assim, se torna possível realizar simulações de enlace com o intuito de se obter curvas que mostram o desempenho do sistema com as configurações desejadas.

Uma vez que um dos maiores problemas de um sistema OFDM foi detalhado (altos valores de PAPR) e foram introduzidas técnicas para mitigação de tal ponto negativo, foram feitas avaliações de tais técnica, também, à sombra das figuras de mérito utilizadas na avaliação do desempenho dos amplificadores. Assim, pretende-se verificar se realmente há benefício em suas utilizações mesmo que a complexidade do sistema aumente. 


\subsection{Desempenho dos Amplificadores}

Foram introduzidos três modelos de amplificadores no Capítulo 3: um amplificador TWT (modelo de Saleh), um amplificador de estado sólido (modelo de Rapp) e um amplificador idealizado limitador de envelope.

Primeiramente, será feita a análise do amplificador modelo Rapp ao se variar o parâmetro $p$, o fator de suavização da função de transferência. As simulações realizadas de um sistema OFDM para a obtenção dos resultados dessa sessão foram feitas com 512 subportadoras, modulação QPSK, prefixo cíclico de tamanho 1/16 do tamanho útil do símbolo e canal AWGN.

A Figura 5.1 ilustra a DT de um sistema OFDM com a utilização do modelo Rapp para o amplificador de potência para $p=2,2.5$ e 3 . Ela foi gerada para $B E R=10^{-3}$. Nota-se que quanto menor é o valor de $p$, maior a degradação do sistema, uma vez que a distorção não linear introduzida por tal dispositivo é maior, fato que pode ser concluído ao se analisar a Figura 3.2.

A conclusão anterior fica evidente quando se raciocina em função dos valores ótimos de OBO.

- $\operatorname{para} p=2$, tem-se $O B O_{\text {ótimo }}=3.03 \mathrm{~dB}$, o que implica em $D T=4.52 \mathrm{~dB}$

- $\operatorname{para} p=2.5$, chega-se à $O B O_{\text {ótimo }}=2.81 \mathrm{~dB}$, o que resulta em $D T=4.36 \mathrm{~dB}$

- $\operatorname{para} p=3$, tem-se $O B O_{\text {ótimo }}=2.78 \mathrm{~dB}$ e, portanto, $D T=4.28 \mathrm{~dB}$

Conclui-se, também, que quanto mais suave é a curva, menor é o valor de $O B O_{\text {ótimo }}$ o que implica em maior eficiência de potência do sistema.

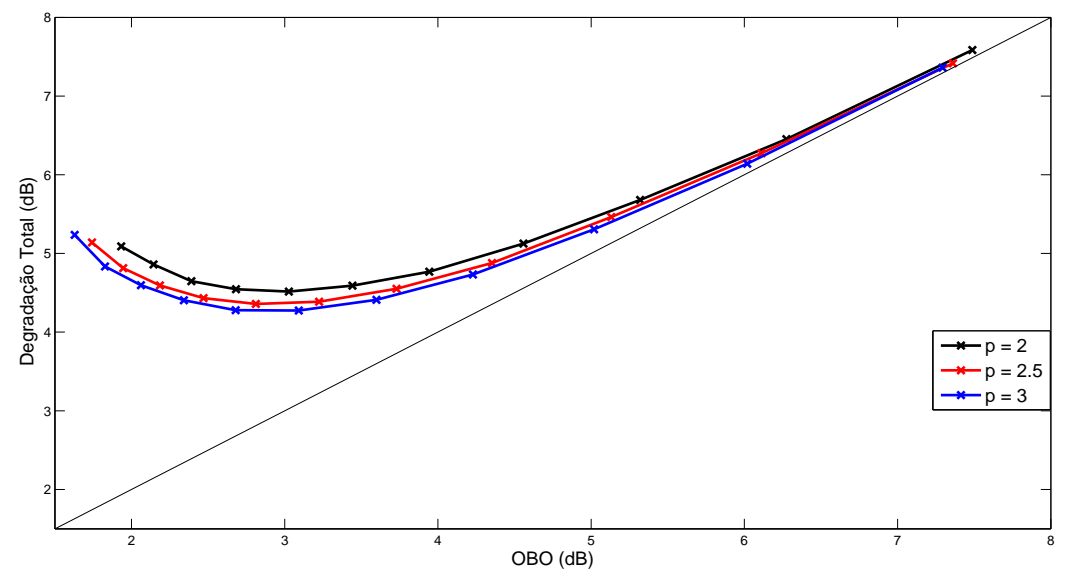

Figura 5.1: Degradação Total de um sistema OFDM utilizando amplificadores Rapp

Já a Figura 5.2 permite fazer as mesmas comparações acima para $B E R=10^{-4}$. Portanto, 
- para $p=2$, tem-se $O B O_{\text {ótimo }}=3.44 \mathrm{~dB}$, o que implica em $D T=5.10 \mathrm{~dB}$

- para $p=2.5$, chega-se à $O B O_{\text {ótimo }}=3.72 \mathrm{~dB}$, o que resulta em $D T=4.86 \mathrm{~dB}$

- para $p=3$, tem-se $O B O_{\text {ótimo }}=3.60 \mathrm{~dB}$ e, portanto, $D T=4.74 \mathrm{~dB}$

Novamente, é possível concluir que quanto mais suave é a curva, menor é a degradação causada pelo dispositivo não linear.

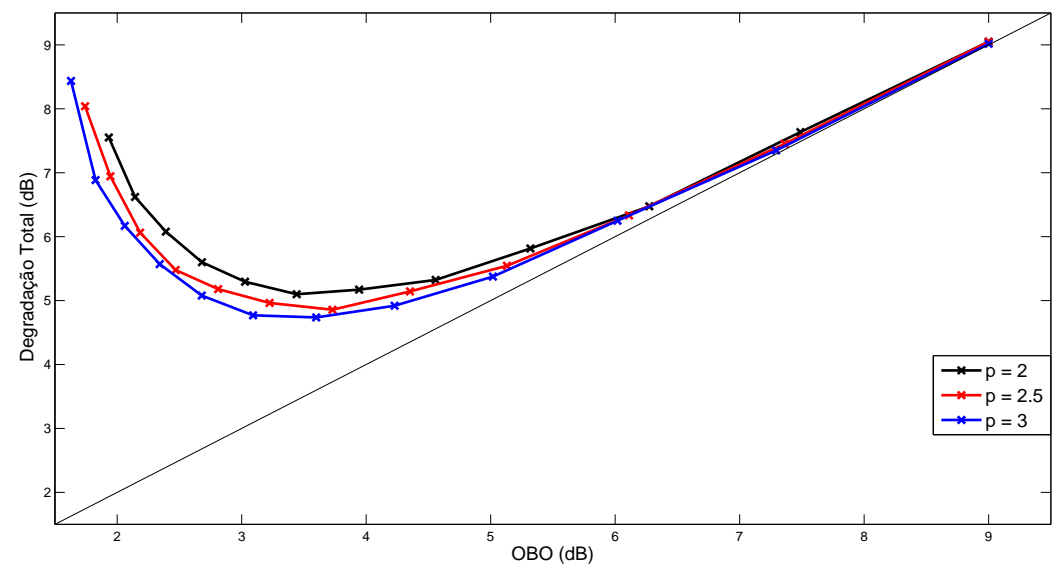

Figura 5.2: Degradação Total de um sistema OFDM utilizando amplificadores Rapp

A Figura 5.3 possibilita a análise do desempenho do sistema na presença de amplificadores sob outro ponto de vista, no domínio da frequência. Ela mostra a ACPR em função do OBO para as três variações de amplificador Rapp analisadas. Novamente, é possível verificar que quanto maior o valor de $p$, melhor é o desempenho do sistema, haja vista que a ACPR é sempre maior. Em relação ao $O B O_{\text {ótimo }}$ para $B E R=10^{-4}$ de cada amplificador, tem-se $A C P R=21.60 d B, 23.00 d B$ e $23.02 d B$, para $p=2,2.5$ e 3 , respectivamente. Isso comprova mais uma vez que ao se trabalhar com $p=3$ em seu ponto ótimo, o desempenho do sistema será melhor.

Portanto, o desempenho de tal amplificador, que se mostrou o mais adequado dentre os outros do mesmo modelo, será comparado com o desempenho dos outros amplificadores estudados: modelo de Saleh e limitador de envelope. As comparações serão feitas novamente em termos de Degradação Total e análises no domínio da frequência.

A Figura 5.4 evidencia a Degradação Total para os três tipos de amplificadores. Para esse caso, $B E R=10^{-3}$. Logo,

- para o modelo de Saleh, tem-se $O B O_{\text {ótimo }}=5.33 \mathrm{~dB}$, o que implica em $D T=7.20$ $d B$

- para o modelo de Rapp com $p=3, O B O_{\text {ótimo }}=2.78 \mathrm{~dB}$ e $D T=4.28 \mathrm{~dB}$ 


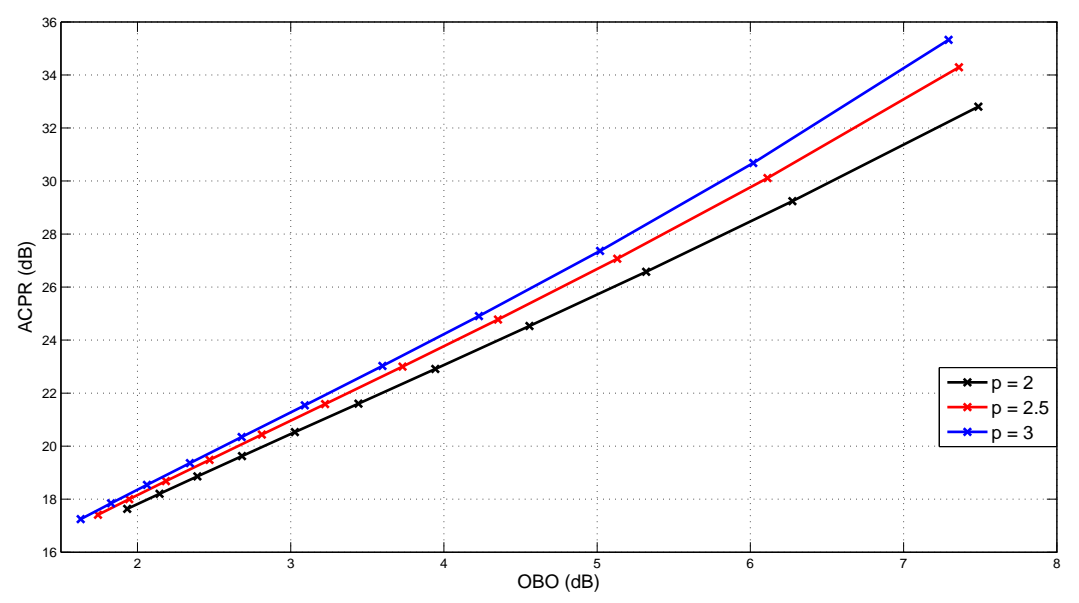

Figura 5.3: ACPR em função do OBO utilizando amplificadores Rapp

- para limitador de envelope, tem-se $O B O_{\text {ótimo }}=2.72 \mathrm{~dB}$ e, $\log \mathrm{o}, D T=4.00 \mathrm{~dB}$

Nota-se, portanto, que o desempenho do sistema na presença do amplificador que é modelado por Saleh é bem pior em relação aos outros dois. Isso é consequência da distorção de fase introduzida por ele, o que não ocorre para os outros, uma vez que suas funções de conversão AM/PM são nulas. Essa distorção de fase é sentida pela constelação do sinal, o que já foi mostrado pela Figura 3.4. É importante salientar que essa distorção de fase poderia ser estimada e compensada na recepção com o intuito de melhorar o desempenho do sistema na presença desse amplificador.

Além disso, ao se comparar o modelo de Rapp $(p=3)$ com o limitador de envelope, percebe-se que o desempenho do sistema com esse é ligeiramente melhor do que com aquele, tanto em relação à eficiência de potência quanto em relação à degradação. Isso já era esperado, visto que o sinal experimenta os efeitos não lineares, ou melhor, atinge a região de saturação do limitador de envelope com uma amplitude maior.

A Figura 5.5 mostra novamente curvas de DT em função do OBO para os três amplicadores. No entanto, ela foi gerada para $B E R=10^{-4}$. Logo,

- para o modelo de Saleh, tem-se $O B O_{\text {ótimo }}=5.33 \mathrm{~dB}$, o que implica em $D T=7.71$ $d B$

- para o modelo de Rapp com $p=3$, chega-se à $O B O_{\text {ótimo }}=3.60 \mathrm{~dB}$, o que resulta em $D T=4.74 d B$

- para limitador de envelope, tem-se $O B O_{\text {ótimo }}=3.23 \mathrm{~dB}$ e, portanto, $D T=4.41 \mathrm{~dB}$

As conclusões são as mesmas obtidas para o caso em que $B E R=10^{-3}$, ou seja, o desempenho do sistema com o amplificador limitador de envelope é o melhor. As únicas 


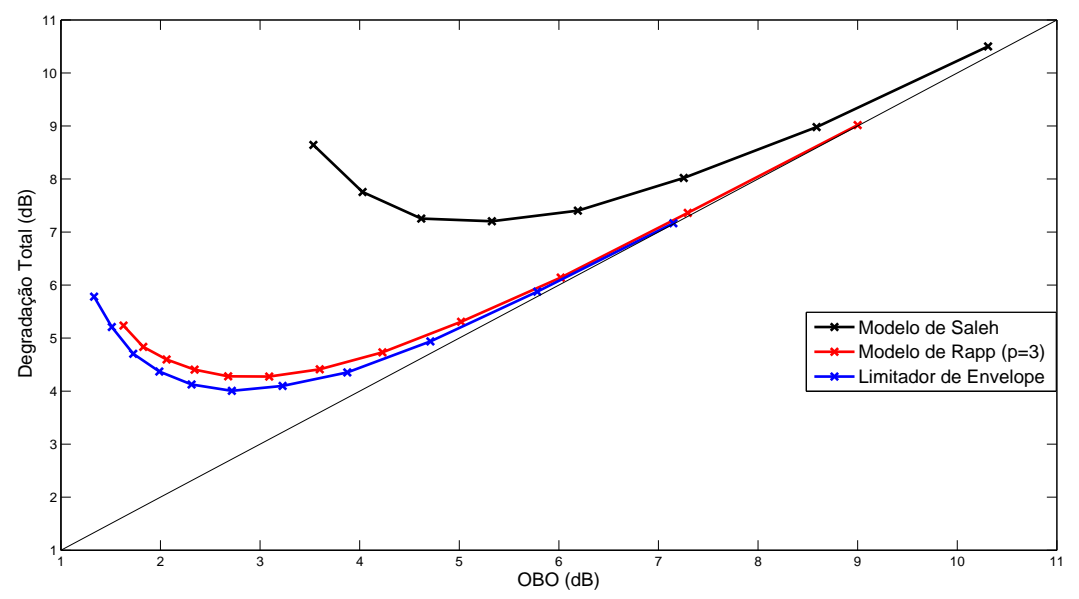

Figura 5.4: Degradação Total para diferentes tipos de amplificadores

diferenças observadas são um leve aumento da DT e um aumento de um pouco mais de $1 d B$ no $O B O_{\text {ótimo }}$ para o modelo de Rapp e para o limitador de envelope. Isso é consequência, justamente, da alteração no valor da $B E R$.

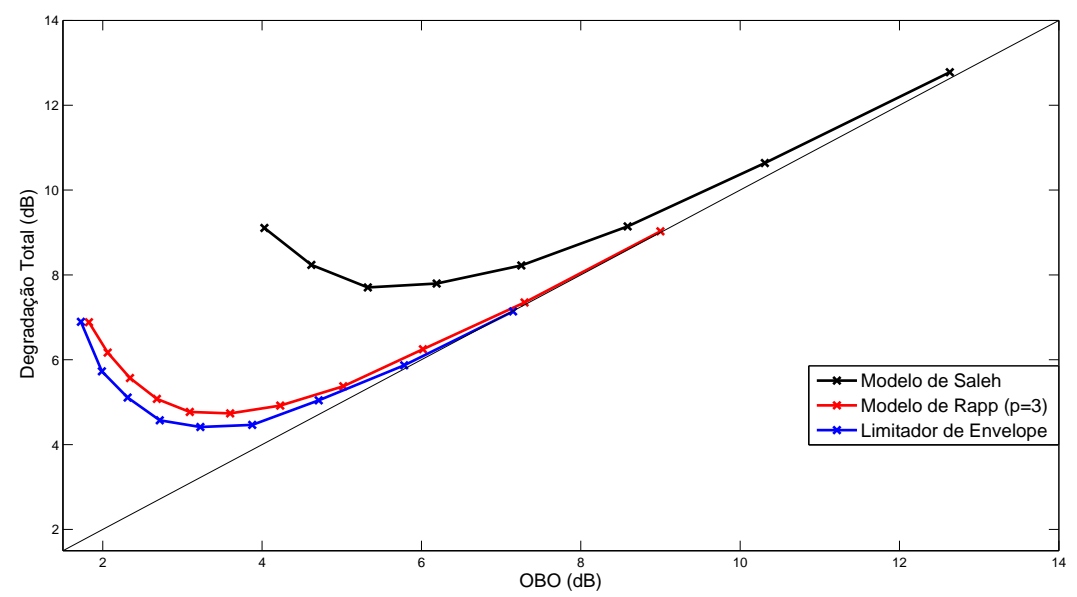

Figura 5.5: Degradação Total para diferentes tipos de amplificadores

Para se ter uma análise mais concreta do desempenho do sistema na presença dos amplificadores, faz-se, também, uma análise no domínio da frequência. Para tanto, a Figura 5.6 ilustra a ACPR em funçao do OBO para os três amplificadores, na qual é possível perceber que independente do valor de $\mathrm{OBO}$, a $\mathrm{ACPR}$ é sempre maior para o limitador de envelope e sempre menor para o modelo de Saleh. Logo, é possível classificar os amplificadores quanto ao bom funcionamento do sistema da seguinte forma: limitador de envelope, modelo de Rapp $(p=3)$ e modelo de Saleh.

Caso o sistema opere com valores de $O B O_{\text {ótimo }}$ para $B E R=10^{-4}$, será observado que $A C P R=25.85 d B, 23.00 d B$ e $22.43 d B$ para o modelo de Saleh, para o modelo de Rapp e para o limitador de envelope, respectivamente. Por causa disso, é possível concluir que o 
modelo que além de possuir distorção de amplitude possui distorção de fase é o que provoca a maior radiação fora de banda.

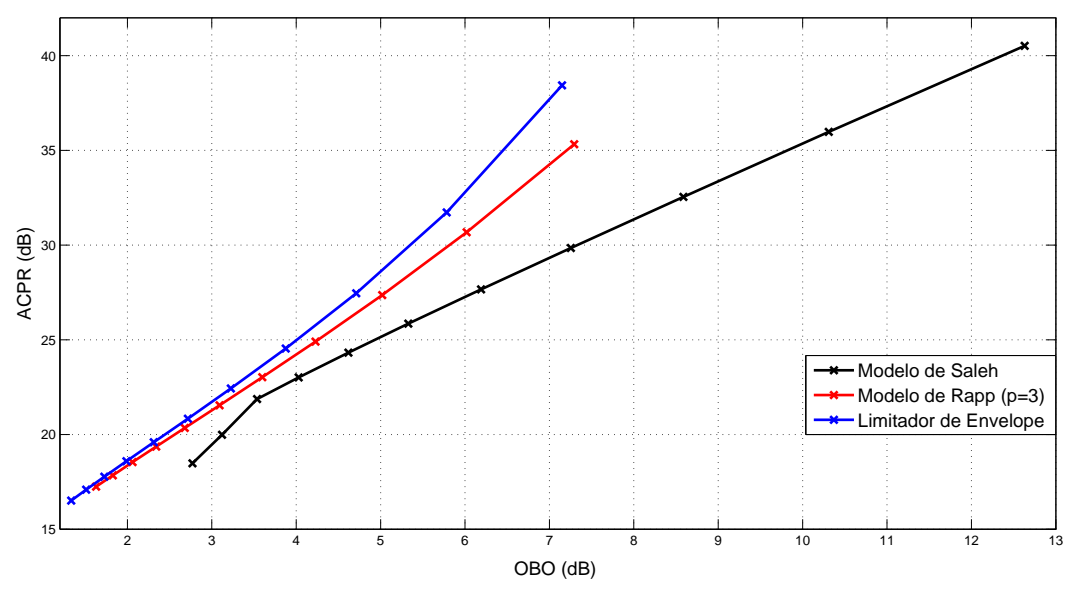

Figura 5.6: Degradação Total para diferentes tipos de amplificadores

Com a finalidade de visualizar o sinal OFDM na frequência e verificar a radiação fora de banda causada por um amplificador não linear, a Figura 5.7 mostra a PSD de sinais OFDM. Nela é possível verificar, no domínio da frequência, um sinal não amplificado e sinais amplificados pelos três tipos de amplificadores detalhados com os valores de $O B O_{\text {ótimo }}$ encontrados para $B E R=10^{-4}$. Além disso, é importante salientar que o sinal foi superamostrado a uma taxa de quatro vezes e que o espaçamento entre as subportadoras é de $15 \mathrm{KHz}$.

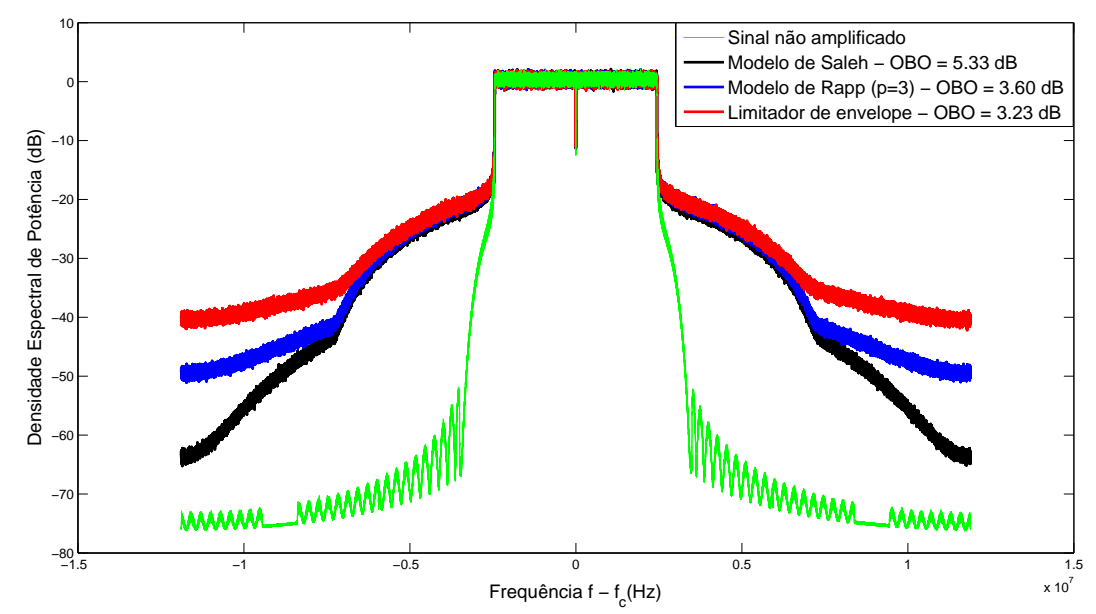

Figura 5.7: Densidade Espectral de Potência de sinais OFDM

\subsection{Desempenho do WiMAX Móvel}

Como não poderia ser diferente, o WiMAX, por ser uma tecnologia que utiliza OFDM, também sofre com os altos valores de PAPR de um sinal. Portanto, é acometido com as 
distorções não lineares causadas pelos amplificadores. Portanto, com a finalidade de avaliar o desempenho da tecnologia em questão na presença de diferentes amplificadores, foram geradas curvas de DT para três tipos de amplificadores: modelo de Saleh, modelo de Rapp $(p=3)$ e limitador de envelope.

Como já foi dito, o sistema WiMAX é simulado por um software desenvolvido com base no padrão IEEE 802.16e. Aqui, as simulações foram realizadas para um sistema OFDM com 512 subportadoras, modulação QPSK e sem codificação. Além disso, o canal utilizado foi o AWGN.

A Figura 5.8 mostra as curvas obtidas com os três amplificadores para $B E R=10^{-3}$, o que nos permite verificar que

- para o modelo de Saleh, tem-se $O B O_{\text {ótimo }}=5.08 d B$, o que implica em $D T=7.29 d B$

- para o modelo de Rapp com $p=3$, chega-se à $O B O_{\text {ótimo }}=3.02 d B$, o que resulta em $D T=4.44 d B$

- para limitador de envelope, tem-se $O B O_{\text {ótimo }}=3.08 \mathrm{~dB}$ e, portanto, $D T=4.13 \mathrm{~dB}$

Assim como foi visto na seção anterior, o desempenho do sistema com o modelo de Saleh é bem inferior aos outros dois casos tanto em termos de eficiência de potência quanto em termos de degradação do sistema. Isso ocorre, pois o modelo em questão introduz distorção de fase no sinal como já foi dito.

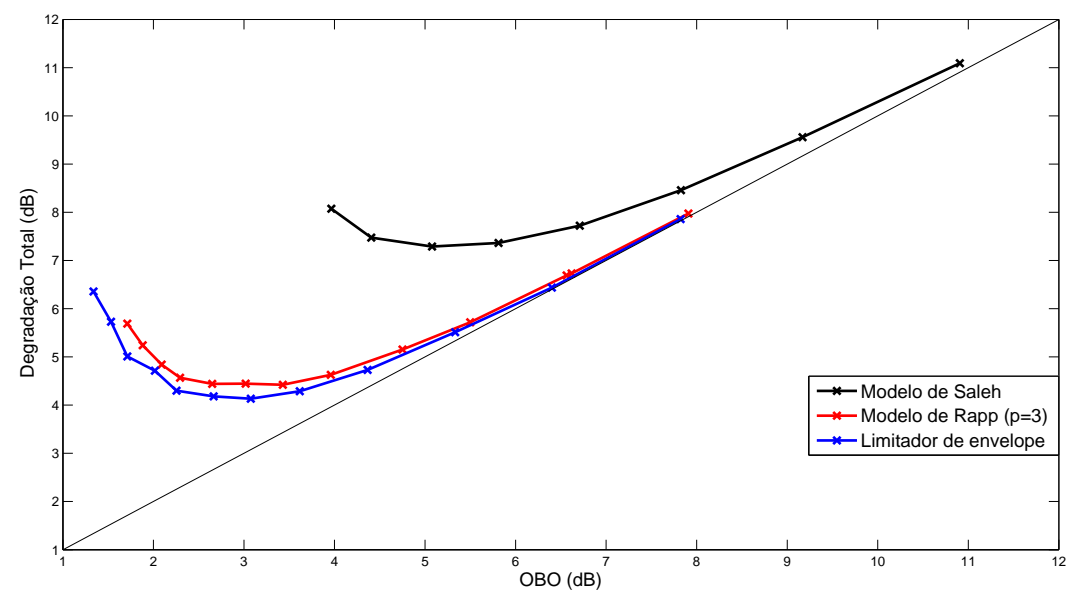

Figura 5.8: Degradação Total para diferentes amplificadores

A Figura 5.9 ilustra as curvas de DT com os três amplificadores para $B E R=10^{-4}$. Como consequência, nota-se que

- para o modelo de Saleh, $O B O_{\text {ótimo }}=5.81 \mathrm{~dB}$, o que implica em $D T=7.93 \mathrm{~dB}$ 
- para o modelo de Rapp com $p=3, O B O_{\text {ótimo }}=3.95 \mathrm{~dB}$, o que resulta em $D T=4.85$ $d B$

- para limitador de envelope, tem-se $O B O_{\text {ótimo }}=3.08 \mathrm{~dB}$ e, portanto, $D T=4.58 \mathrm{~dB}$

Nota-se, portanto, mais uma vez que o desempenho do sistema com o amplificador que segue o modelo de Saleh é o pior. Além disso, também é possível reforçar que com a presença do amplificador limitador de envelope, o sistema possui o melhor desempenho. No entanto, esse caso é idealizado, extremamente complicado de se produzir na realidade, uma vez que sua transição da parte linear para a região de saturação é extremamente brusca.

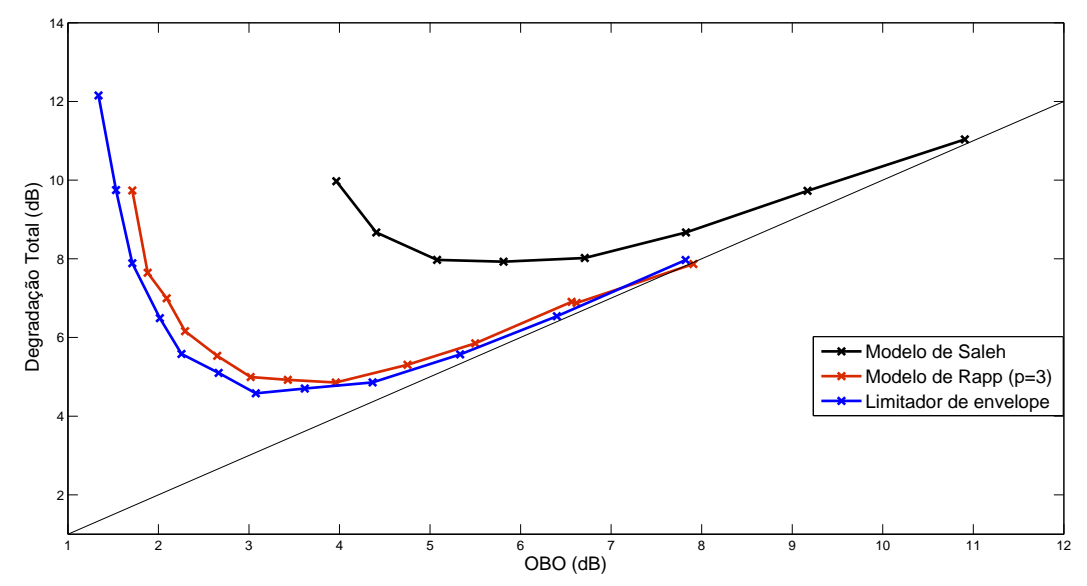

Figura 5.9: Degradação Total para diferentes amplificadores

\subsection{Avaliação do Método de clipping}

No Cápítulo 4 foi visto que ao se limitar um sinal, sua faixa dinâmica de amplitude diminui, haja vista que ele não assumirá valores maiores que o valor de corte. Portanto, sua PAPR diminuirá, o que pode ser visualisado por meio da CDF de PAPR de um sinal. Essa situação é ilustrada pela Figura 5.10, onde a distribuição estatística do PAPR de um sinal OFDM é analisada ao se variar o valor de corte do método de clipping, esse valor de corte é relativo ao pico máximo que o sinal possui.

A Figura em análise foi gerada para um sistema OFDM com 512 subportadoras e modulação QPSK.

Portanto, é perceptível, que ao limitar um sinal OFDM, o seu PAPR, de fato, diminui. No entanto, não se pode afirmar que o desempenho do sistema melhora devido à esse fato. Para mensurar o desempenho de um sistema com a aplicação de tal método, será feita uma análise de degradação total. 


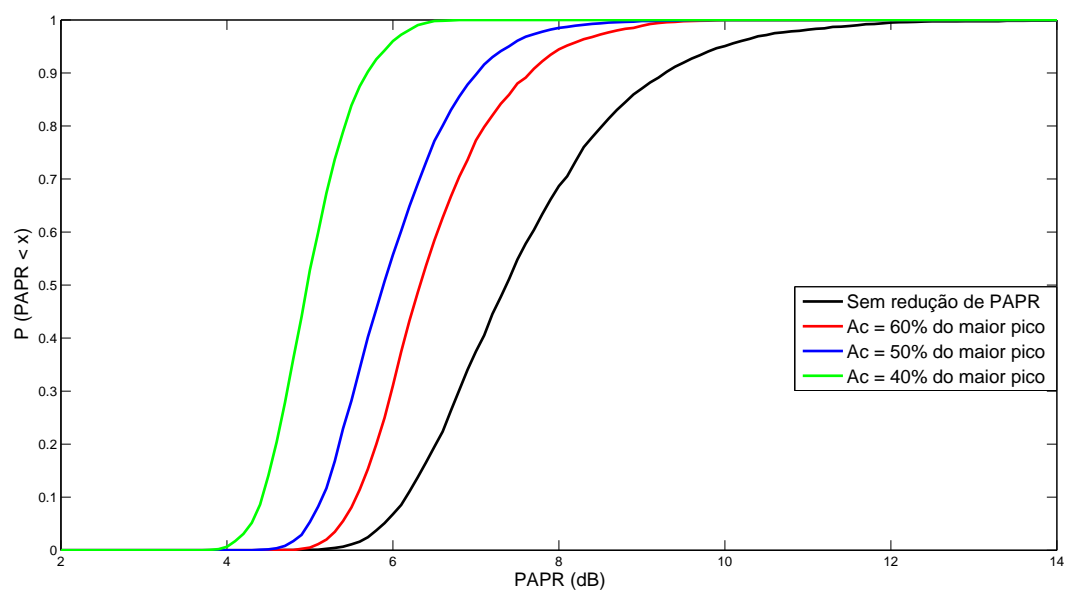

Figura 5.10: CDF de PAPR de um sinal OFDM ao se utilizar o método de clipping

A Figura 5.11 ilustra a DT de um sistema OFDM ao se aplicar o método de clipping utilizando diferentes valores para $A_{c}$, o valor de corte. As curvas foram geradas para um canal AWGN e para $B E R=10^{-3}$. Além disso, foi simulado um sistema com 512 subportadoras, com modulação QPSK e na presença de um amplificador modelo de Rapp $\operatorname{com} p=3$. Nota-se, claramente, que quanto maior é o valor de corte, melhor é o desempenho do sistema, uma vez que quanto maior o valor de $A_{c}$, menor é a influência do método no sinal. Percebe-se, também, que a utilização do método nunca é superior em desempenho em relação a um sinal que passa por tal processamento.

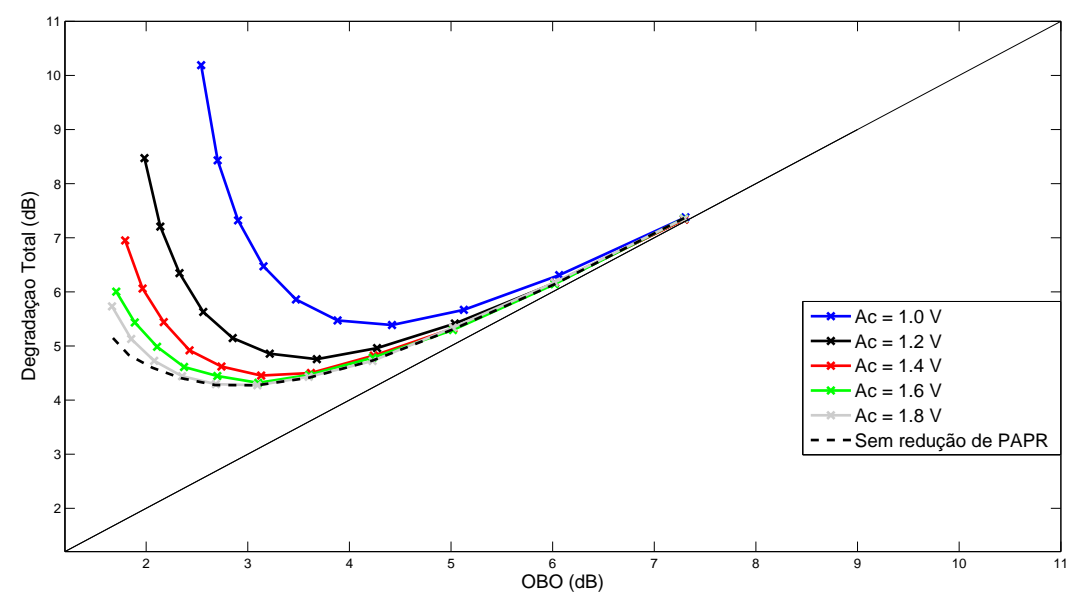

Figura 5.11: Degradação Total com a utilização de clipping

Logo, é possível perceber que a utilização do método em questão, apesar de reduzir o PAPR do sinal, não contribui para melhora em seu desempenho. Isso é explicado pelo fato do clipping ser uma operação não linear, fato que colabora com o aumento da distorção do sinal, que pode ser analisada ao se verificar sua constelação.

As Figuras 5.12 e 5.13 mostram as constelações de sinais modulados em QPSK após 
a aplicação do método de clipping. Para o primeiro sinal, evidenciado pela Figura 5.12, o valor de corte é de $60 \%$ da maior amplitude do sinal; para o segundo, o valor de corte é $40 \%$ de sua maior amplitude. Nota-se, então, que os pontos sinais são deslocados de seus locais originais, acarretando assim em degradação do sistema que é comprovada com a degradação de BER, uma vez que a probabilidade de erro de um bit se torna maior. Além disso, quanto mais baixo é o valor de corte, maior é a degradação sofrida pelo sinal.

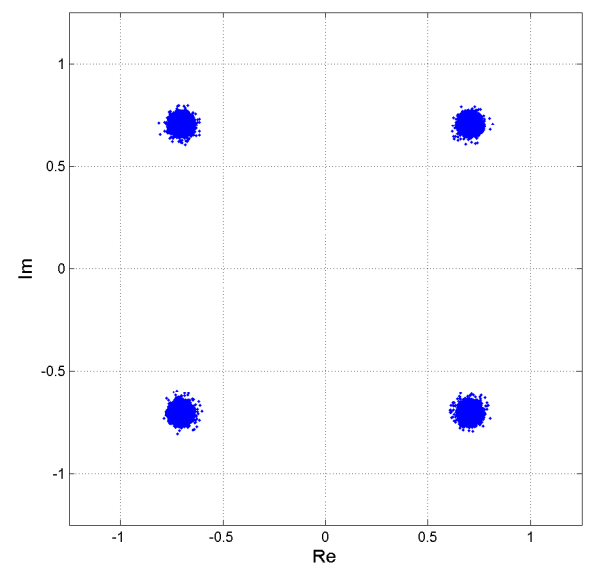

Figura 5.12: Constelação de um sinal OFDM modulado em QPSK limitado em 60\% de sua máxima amplitude

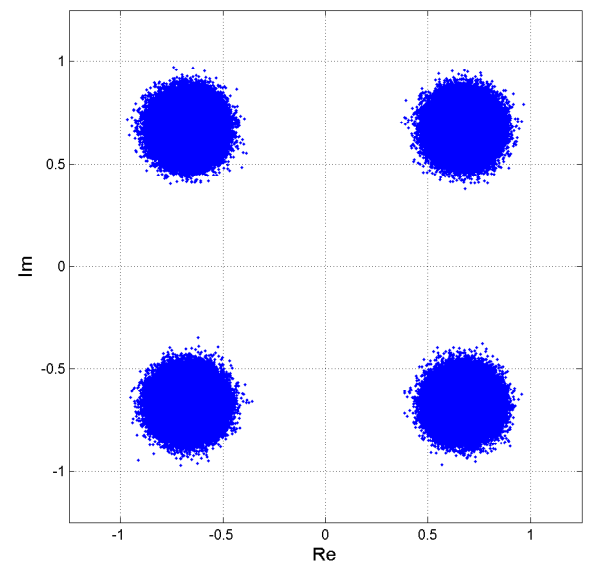

Figura 5.13: Constelação de um sinal OFDM modulado em QPSK limitado em $40 \%$ de sua máxima amplitude

Portanto, conclui-se que o método analisado, apesar de diminuir o PAPR do sinal, não traz ganhos de desempenho nem quando se trata de eficiência de potência. No entanto, a idéia da utilização de tal técnica consiste na adequação do sinal para que ele não possua valores tão altos de amplitude. Desse modo, ele não atinge faixas que podem ser nocivas ao amplificador. Porém, sua utilização só faz sentido se houver uma filtragem após sua 
aplicação com a finalidade de manter o espectro do sinal dentro de uma faixa de frequência aceitável.

\subsection{Avaliação do Método de Jones}

No Capítulo 4 foi detalhado o método de extensão ativa da constelação para redução de PAPR em um sistema OFDM, chamado também de método de Jones. Nessa seção seu desempenho será analisada utilizando, novamente, análise da distribuição estatística do sinal, curva de Degradação Total, curva de ACPR e análise da DSP do sinal.

Para todos os resultados a seguir, foi simulado um sistema OFDM com 512 subportadoras, das quais 420 transmitem dados. A subportadora central (DC) e as mais externas são mantidas nulas para conformação do espectro. O espaçamento entre as subportadoras é de $15 \mathrm{kHz}$ e o prefixo cíclico corresponde a 1/16 do tamanho útil do símbolo. Todos os resultados abaixo foram obtidos considerando um sinal amostrado a uma taxa 4 vezes maior que a amostragem crítica do sinal OFDM.

Primeiramente, será realizada uma análise do seu desempenho com base na distribuição estatística do PAPR do sinal. Para tanto, a Figura 5.14 mostra três curvas de CDF de PAPR em um sinal OFDM, onde é possível observar que a utilização do método realmente diminui a probabilidade de se encontrar altos valores de pico no sinal. Também é possível ver que a diminuição do PAPR é maior quanto menor for o valor $L_{\max }$ selecionado para limitar a amplitude do sinal. Para a situação em questão, o método foi aplicado com 10 iterações.

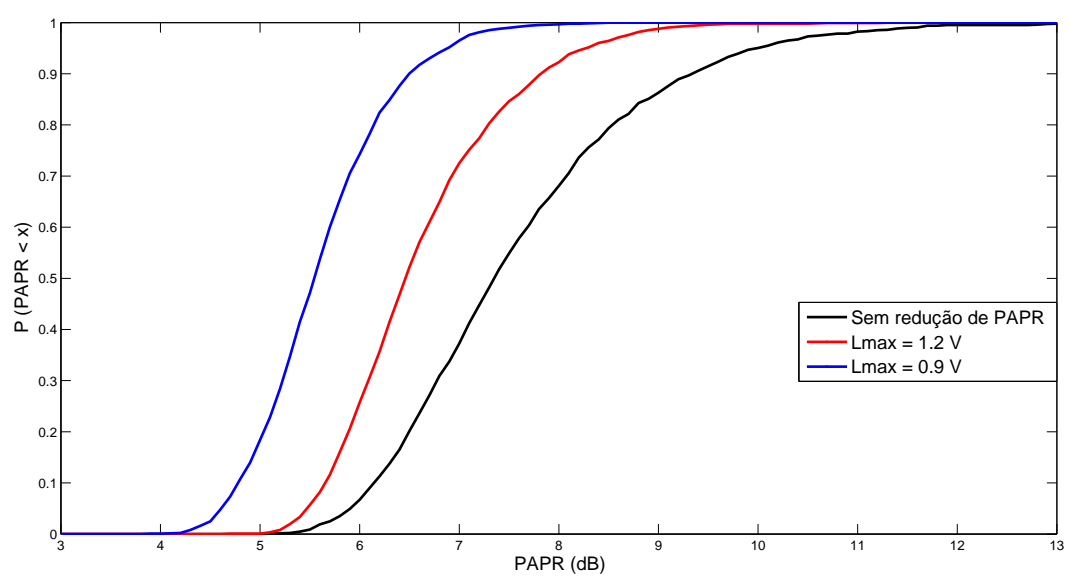

Figura 5.14: CDF de PAPR de um sinal OFDM sem e com redução de PAPR variando o valor de $\operatorname{Lmax}$

No entanto, como já foi visto para o método de clipping, não é suficiente apenas reduzir o PAPR de um sinal, deve-se garantir, também, o bom desempenho do sistema. Um dos 
modos de se avaliar o bom desempenho é por meio de uma curva de degradação total. Para tanto, a Figura 5.15 ilustra tal métrica para um sistem OFDM que utiliza modulação QPSK, é simulado em um canal AWGN e para BER de $10^{-3}$ e $10^{-4}$. O amplificador utilizado foi o limitador de envelope.

Ao se realizar uma análise em termos de valores ótimos, nota-se um ganho de $0.55 \mathrm{~dB}$ de $\mathrm{OBO}$ e uma diminuição de $0.17 \mathrm{~dB}$ na degradação do sistema considerando uma BER de $10^{-3}$. Já para $B E R=10^{-4}$, chega-se a um ganho de $0.70 \mathrm{~dB}$ de potência e a uma diminuição de degradação de $0.33 \mathrm{~dB}$. Portanto, é evidente que a utilização do método de Jones melhora o desempenho do sistema tanto em relação à eficiência de potência quanto à degradação total.

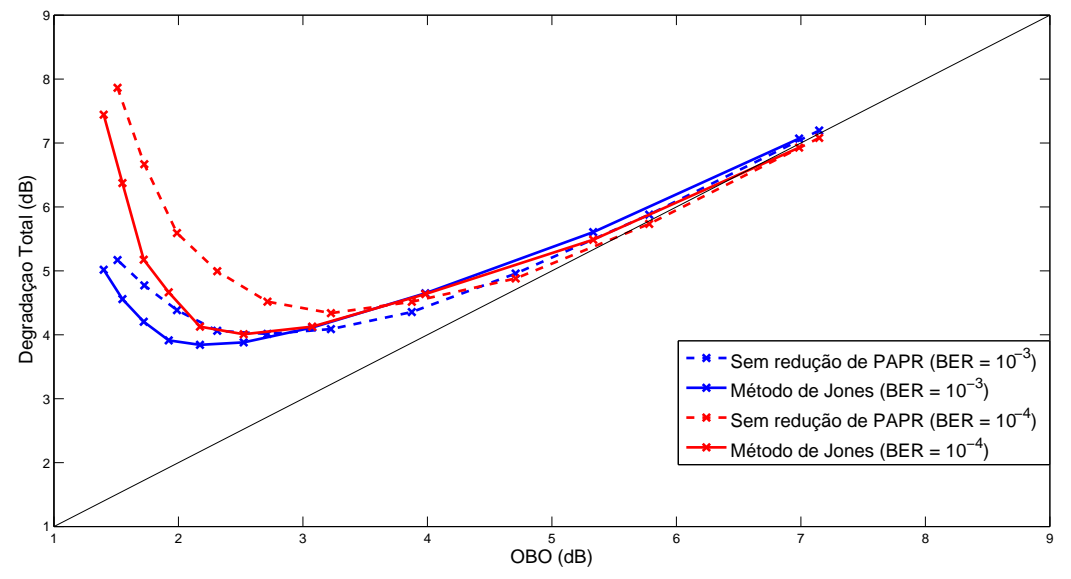

Figura 5.15: Degração Total para avaliação do método de Jones

Apesar de ser evidente que o método é capaz de melhorar o desempenho de um sistema OFDM, não se sabe ao certo quais valores ótimos que devem ser utilizados para os seus parâmetros variáveis: o número máximo de iterações e o valor de $L_{\max }$. Portanto, como, pelo nosso conhecimento, não existe na literatura uma análise considerando a variação desses parâmetros com a utilização de diferentes modulações e diferentes modelos de amplificadores, nos propusemos a fazer este tipo de estudo.

Primeiramente, a atuação do método será verificada para diferentes números de iterações considerando diferentes tipos de modulações. Para isso, foi gerada uma curva de degradação total para diferentes números de iterações. Logo, para cada curva gerada, obteve-se um valor de backoff ótimo, ou seja, obteve-se um backoff ótimo para cada número máximo de iterações. Esse resultado é mostrado na Figura 5.16, que foi obtida em uma simulação com o amplificador modelo Rapp com $p=3$ e com $L_{\max }=1 \mathrm{~V}$ para o método de Jones.

Ao analisá-la é possível verificar que quanto maior o número de iterações utilizado,

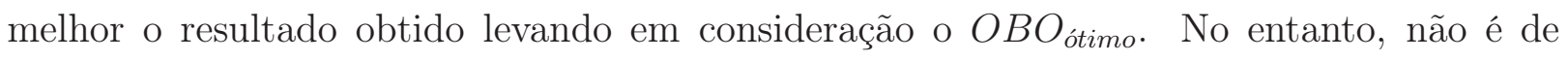
grande valia utilizar um número máximo de iterações muito grande, uma vez que o ganho obtido com ele não é alto em relação a um menor número de iterações. Consequentemente, 
deve-se escolher um número menor com a finalidade de tornar o gasto computacional com o método inferior. Será considerado o número ótimo de iterações aquele que garantir cerca de 0.1 dB abaixo do ganho com o maior número de iterações analisados.

Analisando a curva obtida para a modulação QPSK, nota-se que com 20 iterações obtevese um ganho de $0.87 \mathrm{~dB}$. No entanto, ao se utilizar 10 iterações, obteve-se um ganho de $0.76 \mathrm{~dB}$. Portanto, deve-se optar por utilizar 10 iterações, visto que possui menor esforço computacional do que 20 e considerando que os ganhos são bem próximos.

Já para o 16 QAM, com 20 iterações se observa um ganho de 0.88 dB e com 11, um ganho de $0.83 \mathrm{~dB}$. Logo, deve-se optar por 11 iterações pelo mesmo motivo que se optou por 10 para a modulação QPSK.

Para a modulação 64 QAM, percebe-se um ganho de 0.16 dB com 20 iterações, e de $0.09 \mathrm{~dB}$ para 7 iterações. Nota-se que a aplicação do método para esse caso não é muito vantajosa, pois o ganho obtido é muito pequeno ao se considerar o aumento do esforço computacional. Esse ganho baixo consiste no fato de que para essa modulação a minoria dos pontos da constelação podem ter suas posições alteradas.

A Figura 5.17 evidencia a Degradação Total mínima obtida em função do número máximo de iterações, onde é possível notar um comportamento semelhante às curvas de $O B O_{\text {ótimo }}$, ou seja, são necessárias apenas poucas iterações para o método convergir.

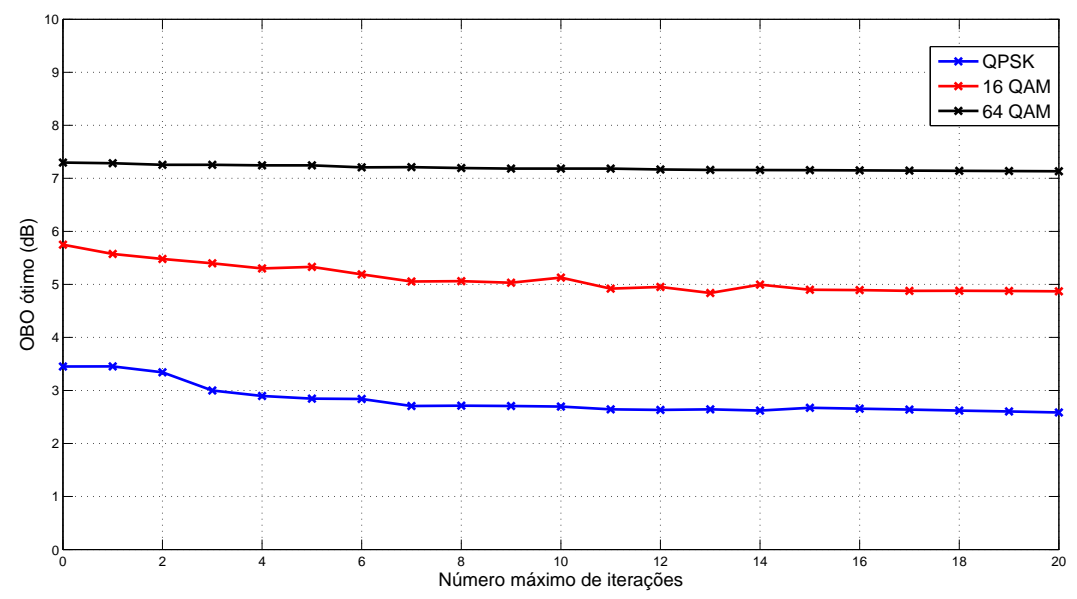

Figura 5.16: OBO ótimo em função do número máximo de iterações

O outro parâmetro ajustável do método de Jones é o valor de $L_{\max }$. Portanto, foram realizadas simulações com a finalidade de se encontrar um valor ideal de $L_{\text {max }}$ para cada amplificador, já que eles possuem comportamentos diferentes. O valor considerado ideal

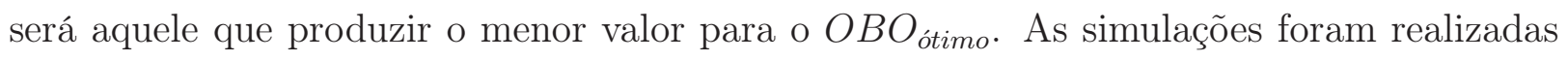
considerando os amplificadores modelo de Rapp $p=2$ e 3 e o limitador de envelope. Suas funções de trasferência são ilustradas na Figura 3.2. Os resultados de simulação se encontram na Figura 5.18, que foi gerada para uma simulação com modulação 16 QAM e 


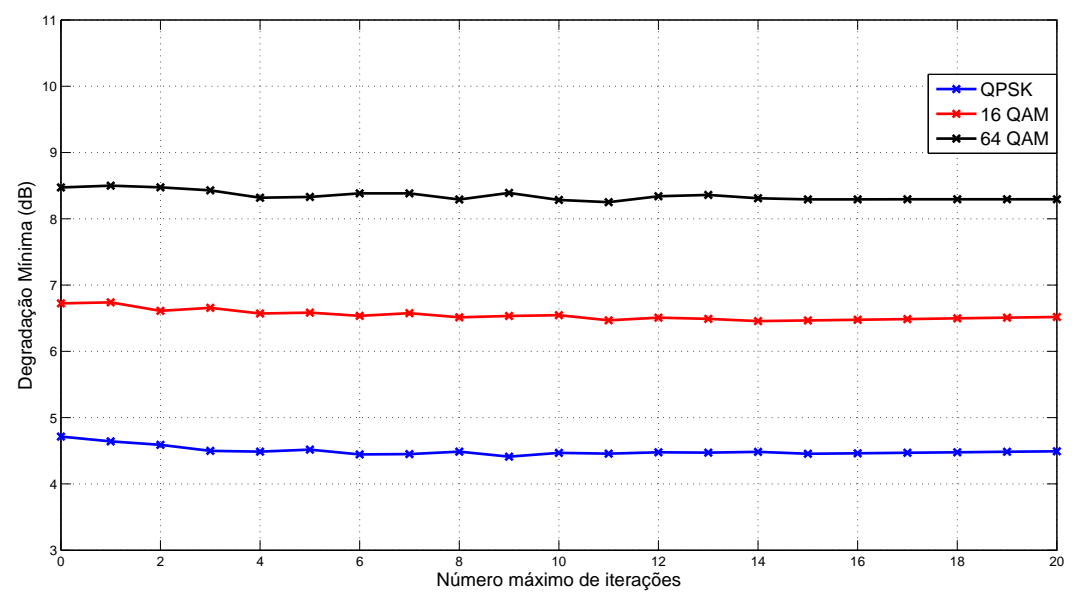

Figura 5.17: Degradação Total mínima em função do número máximo de iterações

10 iterações do método de Jones.

Ao analisá-la para o modelo de Rapp com $\mathrm{p}=2$, obteve-se para o melhor caso um $O B O=5.82 \mathrm{~dB}$ para $L_{\max }=0.8 \mathrm{~V}$. Utilizando $p=3$ para o mesmo modelo, chegou-se a um valor de $O B O=5.02 \mathrm{~d} B \operatorname{com} L_{\max }=0.9 \mathrm{~V}$ para o melhor caso. Já para o limitador de envelope, com um valor de $L_{\max }=1 \mathrm{~V}$, obteve-se $O B O=4.22 \mathrm{~dB}$.

Portanto, nota-se que quanto mais linear é o comportamento do amplificador, menor é o $O B O_{\text {ótimo }}$ e maior o valor de $L_{\max }$ a ser utilizado na aplicação do método, até um máximo de $L_{\max }=1 \mathrm{~V}$. E também interessante ressaltar que para o amplificador limitador de envelope, um modelo idealizado, existe claramente um menor $O B O_{\text {ótimo }}$ para exatamente $L_{\text {max }}=1$, o que já poderia se esperar pelo comportamento do amplificador, que nada mais que é que um limitador neste nível.

A Figura 5.19 ilustra a Degradação Total mínima obtida em função do valor de $L_{\max }$. Neste caso nota-se que, mesmo para o limitador de envelope, o ótimo é limitar o sinal a um valor $L_{\max }<1$.

Deve-se ter em mente que o algoritmo de redução de PAPR é aplicado no sinal amostrado à taxa de saída da IFFT e que ocorre crescimento dos picos após a filtragem do sinal. Desta forma, não é garantido que o sinal super-amostrado ainda estará limitado ao valor $L_{\max }$ selecionado.

Logo, considerando o amplificador modelo de Rapp com $\mathrm{p}=3$, tem-se um valor ideal para $L_{\max }$ e, para as diferentes modulações, tem-se um numero ótimo para o numero máximo de iterações. Logo, com essas informações deseja-se chegar ao maior ganho que o método pode proporcionar para o amplificador em questão e para as diferentes modulações analisadas até aqui.

Na Figura 5.20 é possível verificar em termos de degradação total a utilização do método 


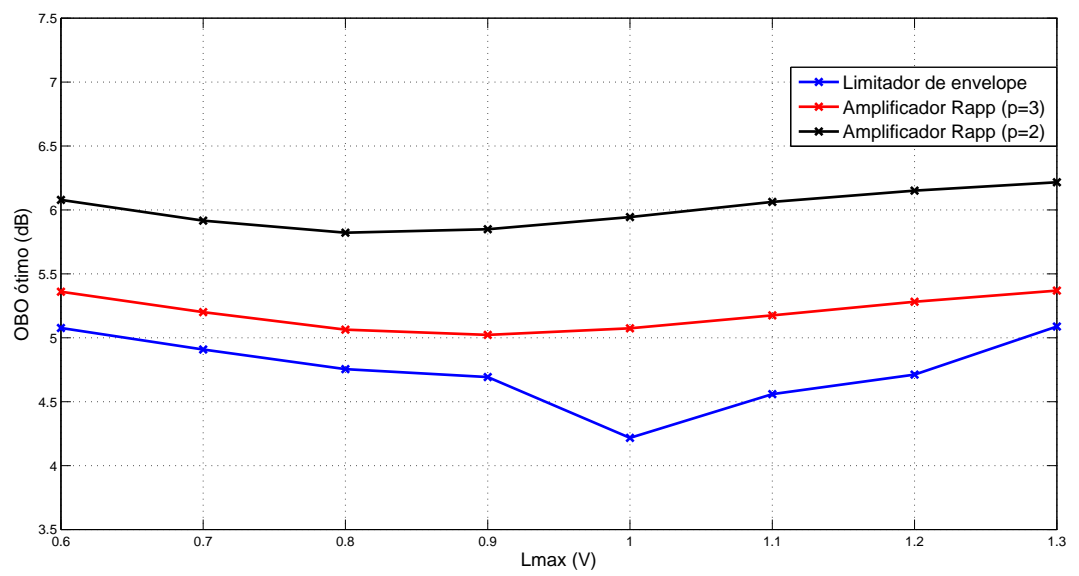

Figura 5.18: OBO ótimo em função do valor de $L_{\max }$

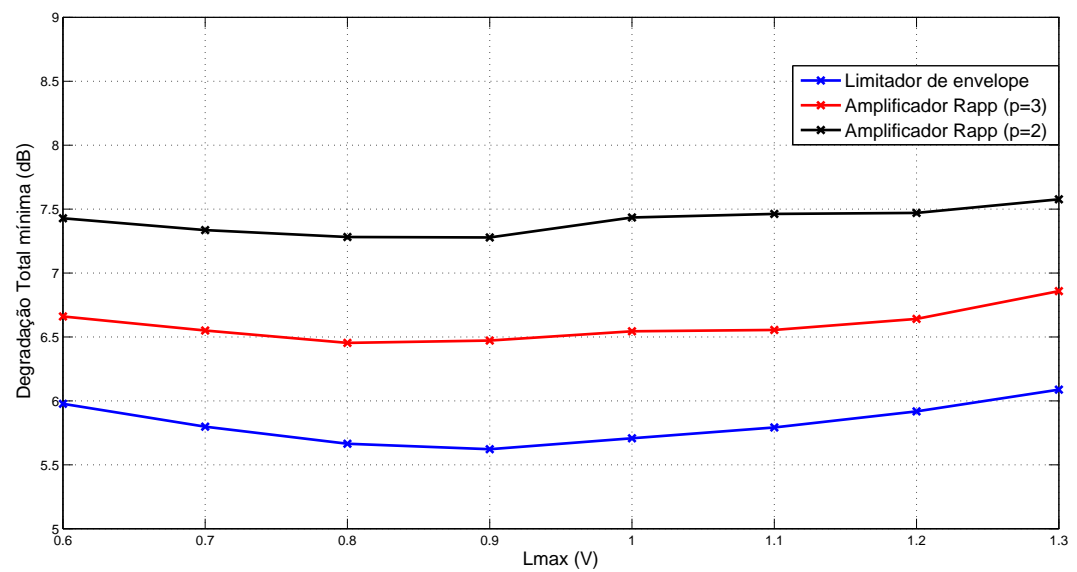

Figura 5.19: Degradação Total mínima em função do valor de $L_{\max }$

de redução de PAPR detalhado aqui. Ela ilustra a situação em que não há redução de PAPR e a situação onde o método é aplicado para as três modulações consideradas. É interessante ressaltar que para o número de iterações foi utilizado o valor ótimo encontrado ao se analisar a Figura 5.16. Além disso, $L_{\max }=0.9 \mathrm{~V}$, visto que foi utilizado o modelo de Rapp com $p=3$ para o amplificador.

Analisando o caso da modulação QPSK, observa-se um ganho de $0.64 \mathrm{~dB}$ em relação ao OBO e um ganho de 0.36 dB para a degradação total. Além disso, existe um acréscimo de $0.23 \mathrm{~dB}$ de ACPR.

Para o 16 QAM, tem-se um ganho de 1.09 dB de $\mathrm{OBO}$ e de $0.34 \mathrm{~dB}$ de degradação. Considerando a ACPR, nota-se uma diminuição de $1.43 \mathrm{~dB}$.

Utilizando 64 QAM, chega-se a $0.48 \mathrm{~dB}$ de ganho para o $\mathrm{OBO}$ e a $0.18 \mathrm{~dB}$ para a degradação total. Nota-se, também, que há um acréscimo de 0.35 dB para ACPR.

Logo, o método utilizado com os parâmetros otimizados continua trazendo ganho e 
somente para o caso em que se utilizou 16 QAM a ACPR diminui. Porém, foi o caso em que se obteve maior ganho considerando o OBO.

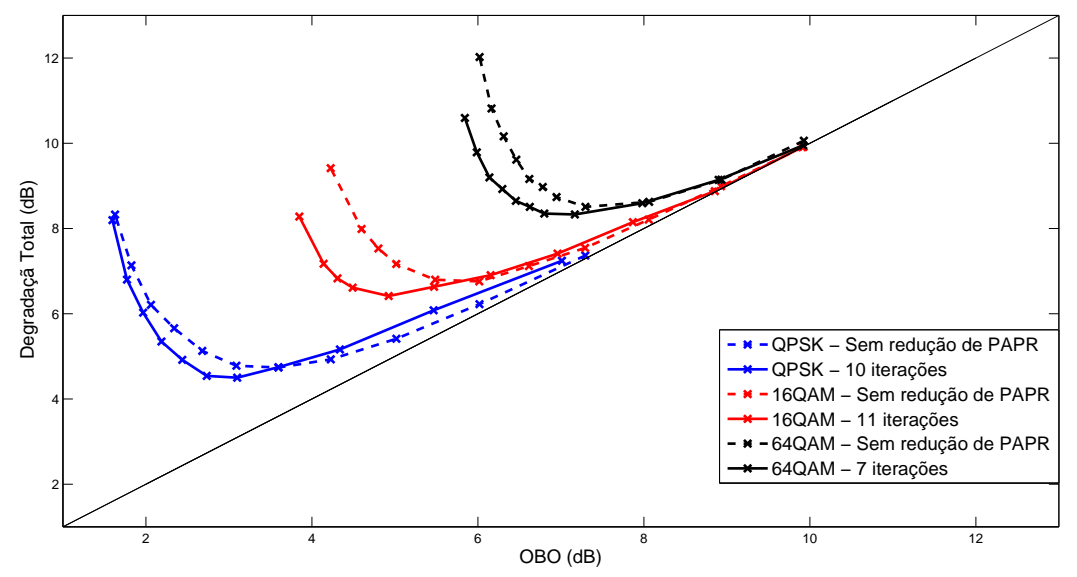

Figura 5.20: Degradação Total utilizando QPSK, 16 QAM e 64 QAM

A Figura 5.21 mostra o espectro de sinais OFDM modulados em 16 QAM e que utilizam 512 subportadoras. Nela é possível visualizar um sinal sem distorção não linear e sinais com e sem redução de PAPR com valores de $O B O_{\text {ótimo }}$ regidos pela Figura 5.20. Além disso, a distorção não linear é causada por um amplificador que segue o modelo de Rapp com $p=3$.

Nota-se que o espectro de um sinal processado pelo método de Jones possui formatação bem semelhante àquele que não possui seu PAPR reduzido. Portanto, o método não causa maiores radiações extra banda e, então, conclui-se que seu desempenho no domínio da frequência também é bom.

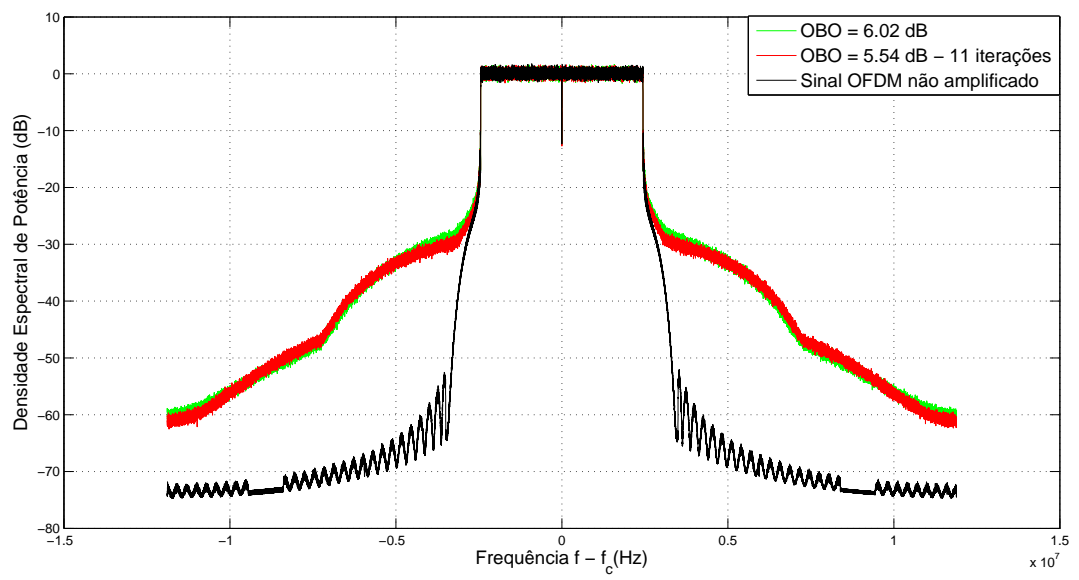

Figura 5.21: Espectro de um sinal OFDM com e sem redução de PAPR, Amplificador Rapp $p=3$

Para reforçar mais ainda tal fato, a Figura 5.22 ilustra a ACPR em função do OBO para um sinal que possui redução de PAPR (11 iterações com o método de Jones) e para um sinal 
que não é processado pelo método. Ambos possuem 512 subportadoras e são modulados em 16 QAM.

Sua análise permite duas conclusões, a primeira, que já foi citada, consiste no fato de que quanto maior é o OBO maior é o ACPR, uma vez que o sinal está na faixa mais linear do amplificador e o sinal não sofre tanto com os efeitos não lineares. A segunda conclusão é que o ACPR para um sinal processado pelo método é sempre maior do que um sinal sem redução de PAPR, ou seja, encontra-se mais potência dentro da banda para um sinal que utiliza o método de Jones.

A segunda conclusão mostra que a utilização de tal método além de melhorar a eficiência de potência do sistema e diminuir sua degradação total, não causa maios radiação extra banda e aumenta o ACPR do sinal. Portanto, conclui-se que o método melhora o desempenho do sistema em mais um quesito.

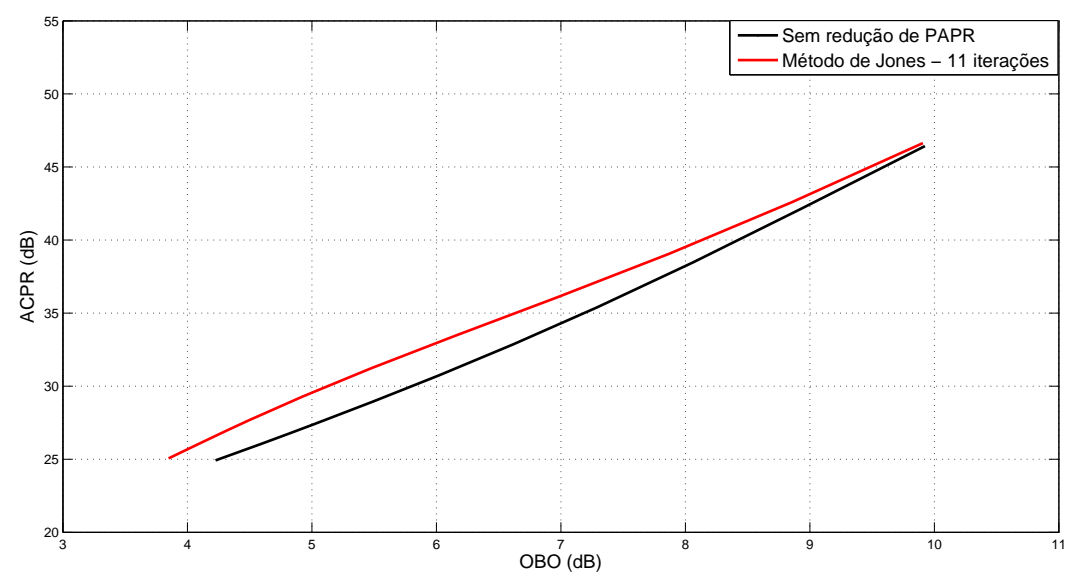

Figura 5.22: Variação do ACPR para diferentes valores de OBO 


\section{Capítulo 6}

\section{Conclusões e Trabalhos Futuros}

Este trabalho apresentou uma análise do desempenho de um sistema de comunicação sem fio que utiliza a técnica de transmissão OFDM na presença de amplificadores não lineares. Foi visto no Capítulo 2 que o OFDM possui diversas vantagens, o que explica sua imensa aceitação na composição de tecnologias sem fio. Por causa disso, a análise de um sistema que a tem como base se torna importante. Além disso, para exemplificar o desempenho de um padrão de tecnologia existente, foi analisado o desempenho do WiMAX móvel na presença de três tipos de amplificadores não lineares.

Primeiramente, foi realizada uma análise estatística de uma figura de mérito (PAPR) de um sinal OFDM, o que possibilitou a percepção da alta variação de amplitude desse sinal. Foi visto, também, que quanto maior é o número de subportadoras utilizadas pelo sinal, maior é a probabilidade de ocorrência de altos valores de amplitude. Outro aspecto importante a ser ressaltado é a importância da superamostragem na análise de tal figura de mérito, haja vista que se não há superamostragem, os resultados obtidos são muito otimistas em relação à realidade.

Uma vez que um sinal OFDM sofre grande variação de amplitude, a presença de um amplificador de potência deve ser observada com cuidado, já que ele possui comportamento não linear. Para tanto, na avaliação do desempenho de um sistema OFDM um modelo de amplicador deve estar presente. Logo, três tipos de amplificadores foram detalhados: o amplificador TWT, que possui forte distorção de fase; o amplificador modelo Rapp, que é um amplificador não linear de estado sólido; o limitador de envelope, que constitui um modelo idealizado.

A avaliação do desempenho do sistema na presença dos amplificadores foi realizada no Capítulo 5 por meio de simulações de enlace e à sombra das figuras de mérito introduzidas no Capítulo 3 como, por exemplo, Degradação Total e ACPR, que possibilitaram uma análise tanto no domínio temporal quanto no domínio da frequência. Notou-se, portanto, que quanto maior é o valor do parâmtro $p$ do modelo de Rapp, melhor é o desempenho do sistema. Além disso, o desempenho com o amplificador TWT foi o pior e com o limitador 
de envelope, o melhor. Com o modelo de Rapp, obteve-se resultados intermediários aos dois outros amplificadores. Deve ser ressaltado que quando se utilizou o amplificador TWT, não houve estimação nem compensação de fase na recepção, tornando seu desempenho pior do que poderia ser caso fosse realizada a estimação e compensação. Portanto, deve-se realizar essa tarefa em trabalhos futuros.

O desempenho de um sistema WiMAX também foi analisado na presença dos amplificadores não lineares. Novamente, foi possível perceber que o melhor resultado é obtido com o limitador de envelope, o pior, com o amplificador TWT e que o modelo de Rapp possui desempenho intermediário aos dois.

Consequentemente, com a finalidade de melhorar os resultados obtidos para um sistema OFDM na presença de um amplificador não linear, duas técnicas de redução de PAPR foram introduzidas: o clipping e o método de Jones. Foi observado que, de fato, esses métodos reduzem o PAPR do sinal OFDM.

No entanto, observou-se que o desempenho de um sistema OFDM piora com a utilização do clipping, pois este constitui uma operação não linear. Sua utilização é indicada apenas para limitar os valores que o sinal pode assumir, o que evita riscos ao amplificador. Além disso, deve-se filtrar o sinal após sua utilização com o intuito de manter o espectro dentro de uma faixa de frequência aceitável.

Diferentemente do clipping, o método de Jones além de reduzir o PAPR do sinal colabora tanto com o aumento da eficiência de potência do sistema quanto com a diminuição de sua degradação e ainda não gera radiações extra banda. Além disso, sua utilização não necessita grande número de iterações, o que não aumenta em grande escala a complexidade computacional do sistema. Foi visto também que existe um valor ótimo de $L_{\max }$ para os diferentes amplificadores analisados, uma vez que o comportamento de suas funções de transferência são diferentes.

Outro ponto importante a ser destacado é que quanto maior a ordem da técnica de modulação utilizada pelo sinal, menor é a influência do método, uma vez que menor é a porcentagem de pontos sinais que podem ser alteradas quando a ordem da modulação aumenta.

Por fim, seguindo o estudo realizado aqui, algumas tarefas ainda podem ser realizadas com a finalidade de se obter outros resultados. Algumas dessas tarefas são:

- Análise do desempenho da tecnologia LTE na presença dos diferentes amplificadores estudados. Para tanto, deve-se realizar os mesmos tipos de simulações realizadas aqui em um simulador de LTE

- Implementação e análise do desempenho do clipping e do método de Jones em um simulador da tecnologia LTE 
- Estudo e implementação de novas técnicas de redução de PAPR tanto em um sistema OFDM qualquer quanto em simuladores das tecnolgias WiMAX e LTE

- Análise do desempenho dos sistemas com a utilização das novas técnicas de redução de PAPR 


\section{REFERÊNCIAS BIBLIOGRÁFICAS}

[1] 1999, I. S. 802.11a. Part 11: Wireless lan medium access control (mac) and physical layer (phy) specifications Ú high-speed physical layer in the 5 ghz band.

[2] 2005, I. S. 802.16e. Ieee standard for local and metropolitan area networks part 16: Air interface for fixed broadband wireless access systems. May 2004.

[3] AL., H. E. et. Technical solutions for the 3g long term evolution. IEEE Commun. Mag., p. 38-44, March 2006.

[4] SCHULZE, H.; LüDERS, C. Theory and Applications of OFDM and CDMA. [S.l.]: John Wiley e Sons, 2005.

[5] HERRAIZ, M. D. Multicarrier communication systems with low sensitivity to nonlinear amplification. 2008.

[6] NUAYMI, L. WiMAX: Technology for Broadband Wireless Access. [S.l.]: John Wiley and Sons, 2007.

[7] OCHIAI, H.; IMAI, H. Performance analysis of deliberately clipped ofdm signals. IEEE Trans. Commun., v. 50, p. 89-101, February 2002.

[8] ANDREWS ARUNABHA GHOSH, R. M. J. G. Fundamentals of WiMAX. [S.l.]: Prentice Hall, 2005.

[9] OCHIAI, H.; IMAI, H. Block coding scheme based on complementary sequences for multicarrier signals. IEICE Trans. Fundamentals, E80-A, p. 2136-2143, November 1997.

[10] NIKOPOUR, H.; JAMALI, S. On the performance of ofdm system over a cartesian clipping channel: A theoretical approach. IEEE Transactions on Wireless Communication, n. 3(6), p. 2083-2096, 2004.

[11] NEE, R. van; WILD, A. de. Reducing the peak-to-average ratio of ofdm. In Vehicular Technology Conference, n. 3, p. 2072-2076, 1998.

[12] SALEH, A. A. M. Frequency-independent and frequency-dependent nonlinear models for twt amplifiers. IEEE Transaction on Communications, v. 29, p. 1715-1720, November 1981. 
[13] RAPP, C. Effects of the hpa-nonlinearity on a 4-dpsk/ofdm signal for a digital sound broadcasting system. Tech. Conf. ECSC, October 1991.

[14] WILKINSON, T.; JONES, A. E. Minimization of the peak-to-mean envelope power ratio of multicarrier transmission schemes by block coding. Proc. of IEEE Vehicular Technology Conference, p. 825-829, July 1995.

[15] PAUlI, M.; KUCHENBECKER, H. P. Minimization of the intermodulation distortion of a nonlinearly amplified ofdm signal. Wireless Personal Communications, v. 4, n. 1, p. 93-101, Jan 1997.

[16] HUBER, S. H. M. e J. Ofdm with reduced peak-to-average power ratio by optimum combination of partial transmit sequences. Electronics Letters, v. 33, n. 5, p. 368-369, Feb 1997.

[17] CIMINI, J. e. N. R. S. L. J. Peak-to-average power ratio reduction of an ofdm signal using partial transmit sequences with embedded side information. in Proc. Globecom, 2000 .

[18] TELlambURA, A. D. S. J. e C. Reducing the peak-to-average power ratio of orthogonal frequency division multiplexing signal through bit or symbol interleaving. in Electronics Letters, v. 36, n. 13, p. 1161-1163, Jun 2000.

[19] DU, N. C. B. e. J. Z. Z. Selective time-domain filtering for reduced-complexity papr reduction in ofdm. in IEEE Trans. Veh. Tech., p. 1161-1163, Mar 2009.

[20] KRONGOLD, B. S.; JONES, D. L. Selective time-domain filtering for reducedcomplexity papr reduction in ofdm. in IEEE Trans. broadcasting, v. 49, n. 3, p. 25, Set 2003. 